\title{
Removal of Methylene Blue Dye From Aqueous Solution Using PDADMAC Modified ZSM-5 Zeolite as a Novel Adsorbent
}

Sabarish Radoor ( $\sim$ sabarishchem@gmail.com )

King Mongkut's University of Technology North Bangkok https://orcid.org/0000-0002-0420-0240 Jasila Karayil government women's polytechnic college kozhikode

Aswathy Jayakumar

King Mongkut's University of Technology North Bangkok

Jyotishkumar Parameswaranpillai

King Mongkut's University of Technology North Bangkok

Suchart Siengchin

King Mongkut's University of Technology North Bangkok

\section{Research Article}

Keywords: ZSM-5 Zeolite, Poly (diallyl dimethylammonium chloride), Methylene blue, Adsorption isotherm, Kinetics

Posted Date: February 13th, 2021

DOI: https://doi.org/10.21203/rs.3.rs-211769/v1

License: (1) This work is licensed under a Creative Commons Attribution 4.0 International License. Read Full License

Version of Record: A version of this preprint was published at Journal of Polymers and the Environment on March 11th, 2021. See the published version at https://doi.org/10.1007/s10924-021-02111-8. 


\title{
Removal of methylene blue dye from aqueous solution using PDADMAC modified ZSM-5 zeolite as a novel adsorbent
}

\author{
Sabarish Radoor ${ }^{*}$, Jasila Karayil ${ }^{2}$, Aswathy Jayakumar ${ }^{1}$, Jyotishkumar Parameswaranpillai ${ }^{1}$, \\ Suchart Siengchin ${ }^{1}$
}

1. Materials and Production Engineering, The Sirindhorn International Thai-German Graduate School of Engineering (TGGS), King Mongkut's University of Technology North Bangkok, Bangkok 10800, Thailand

2. Government Women's Polytechnic College, Calicut, Kerala, India

*Corresponding authors:

email: sabarishchem@gmail.com

\section{Abstract}

In the present work, we modified ZSM-5 zeolite using a bio polymer poly (diallyl dimethyl ammonium chloride) and employed it for the removal of cationic dye, methylene blue from aqueous solution. The chemical and physical properties of the modified ZSM-5 zeolite were investigated using XRD, FTIR, SEM, TEM, nitrogen adsorption, TGA and ${ }^{27} \mathrm{Al}$ NMR. Modified ZSM-5 zeolite possesses high surface area and pore diameter which was confirmed from SEM, TEM and nitrogen adsorption analysis. Adsorption of methylene blue on zeolite was investigated by batch adsorption technique. The effect of different parameters such as zeolite dosage, initial methylene blue concentration, temperature, $\mathrm{p}^{\mathrm{H}}$ and contact time on the adsorption process was discussed. Maximum adsorption capacity $(4.31 \mathrm{mg} / \mathrm{g})$ was achieved using $0.1 \mathrm{~g}$ of modified ZSM-5 zeolite at the optimum conditions (initial dye concentration: 10 $\mathrm{mg} / \mathrm{L}, \mathrm{pH}: 10$, temperature: $30^{\circ} \mathrm{C}$ and contact time: $300 \mathrm{~min}$ ). The experimental data were fitted into Langmuir and Freundlich models and the results indicate that the adsorption process followed Freundlich isotherm. Kinetic data were investigated using pseudo-first-order and pseudo-second-order models. Kinetic analysis indicates that pseudo-second-order model is more suitable to describe adsorption of MB on modified ZSM-5 zeolite. The reusability test suggests that the adsorbent could be reused at least six times without significant loss in removal efficiency.

Keywords: ZSM-5 Zeolite; Poly (diallyl dimethylammonium chloride); Methylene blue; Adsorption isotherm; Kinetics 


\section{Introduction}

Water pollution has drastically increased in the last few decades due to the rapid growth of urbanisation and industrialization (Dil et al., 2016; Sharifpour, Khafri, Ghaedi, Asfaram, \& Jannesar, 2018). Chemical industries such as textile, printing, paper, pharmaceutical, food, leather, photography, paints etc. are dumping tons and tons of untreated water to nearby lakes, rivers and sea and thereby accelerates the manmade water pollution (Kumari et al., 2020; Sharifpour et al., 2018; Sun, Cao, \& Lu, 2011; X. S. Wang, Zhou, Jiang, \& Sun, 2008). Textile industries are one of the major contributors of water pollution and dispose large amount of toxic dyes to water bodies (Talaiekhozani, Reza Mosayebi, Fulazzaky, Eskandari, \& Sanayee, 2020; Tkaczyk, Mitrowska, \& Posyniak, 2020). Dyes are organic compounds which impart colour to the materials such as fabrics, paper, leather, food stuff etc.(Adegoke \& Bello, 2015) . Based on their nuclear structures, dyes are classified into anionic, cationic and non-ionic dyes. Among them, cationic dye is known to be more toxic (Adegoke \& Bello, 2015; Alver \& Metin, 2012; Mall, Srivastava, \& Agarwal, 2006).

Methylene blue (MB) is a sapphire-coloured cationic dye which belongs to phenothiazine family (Figure 1). It has been used as colorant, biological stain and redox indicator. However, due to its carcinogenic and mutagenic nature $\mathrm{MB}$ is considered as a harmful water pollutant (Khodaie, Ghasemi, Moradi, \& Rahimi, 2013; Naushad et al., 2019). Hence researchers have implemented various physical, chemical and biological treatment methods for removing $\mathrm{MB}$ from water (Sizmur, Fresno, Akgül, Frost, \& Moreno-Jiménez, 2017; Zhao et al., 2018). Adsorption is one of the frequently used methods for removal of $\mathrm{MB}$ from aqueous solution. The interest in this technique mainly comes from its salient features such as low-cost, simplicity and easy handling (Benkhaya et al., 2019; Nas et al., 2019; Vakili et al., 2019). There are several reports of using different adsorbent for the removal of MB from water (Jawad \& Abdulhameed, 2020; Pang et al., 2020; Pomicpic, Dancel, Cabalar, \& Madrid, 2020; Shooto, Thabede, Bhila, Moloto, \& Naidoo, 2020). For instance, Mouni et al. (Mouni et al., 2018) reported that Algerian kaolin is an effective adsorbent for the removal of MB. The superior adsorption of kaolin is attributed to its high surface area. Huang et al. studied the removal efficiency of MB using graphene oxide modified zeolite (Huang et al., 2019) and kaolin (He et al., 2018). The authors reported that the introduction of graphene oxide (GO) into zeolite/kaolin increases the active site on the composites and consequently improves its adsorption performance. Rida et al. (Rida, Bouraoui, \& Hadnine, 2013) studies revealed that kaolin is a better adsorbent than zeolite for removing MB from aqueous solution. The high adsorption 
capacity (96\%) of clay is attributed to its high surface area and pore diameter. Cao et al.(Cao, Pan, Shi, \& Yu, 2018) reported high MB removal efficiency and good regenerability of porous chitin. Aysan et al. (Aysan, Edebali, Ozdemir, Celik Karakaya, \& Karakaya, 2016) and coworkers employed chabazite to remove MB from aqueous environment and propose it as an excellent adsorbent for MB. Mayab et al. (Miyah, Lahrichi, Idrissi, Khalil, \& Zerrouq, 2018) successfully employed a low-cost bio adsorbent (walnut shell powder) to remove MB from aqueous solution.

Both natural and synthetic adsorbents have been successfully employed for the removal of dye from the aqueous effluents. Nevertheless, most of the adsorbents are expensive, toxic, nonbiodegradable, poor in regeneration capability and selectivity. Therefore, finding a cost effective and biodegradable adsorbent is a relevant area of research (Aichour \& ZaghouaneBoudiaf, 2019; Shittu et al., 2019; Soliman, Moustafa, Aboud, \& Halim, 2019; Ullah, Sun, Gul, $\&$ Bai, 2020). Zeolites are naturally occurring crystalline aluminosilicate mineral with porous structure. Owing to its high surface area, pore volume and pore diameter, zeolites have been increasingly studied for the liquid adsorption of dissolved pollutants in water (Guo et al., 2011; Han et al., 2009; X. Jin, Jiang, Shan, Pei, \& Chen, 2008; S. Wang \& Zhu, 2006). The characteristic properties of zeolites such as pore size, pore volume and surface area could be modified by different templates starch, cellulose, chitosan, agricultural waste etc. (J. Jin et al., 2012; Krishnamurthy, Msm, \& Kanakkampalayam Krishnan, 2016; Sabarish \& Unnikrishnan, 2017, 2019). Previous studies indicate that uniform pores and well-defined surface area in modified zeolite is responsible for enhancing its adsorption efficiency (Radoor, Karayil, Parameswaranpillai, \& Siengchin, 2020a; Sari, Younesi, \& Kazemian, 2014). Drumm et al. (Drumm et al., 2018)reported high dye removal efficiency of mesoporous ZSM-5 zeolite synthesized through templating method. Meanwhile, Armagan et al. (Armagan, Turan, \& Karadag, 2010; Armağan, Turan, Özdemir, \& Çelik, 2004) examined the dye removal ability of natural and modified zeolites. The adsorption studies suggest that modified zeolite is superior to unmodified zeolites.

In this context, it is worthwhile to develop a modified zeolite for the adsorption of MB dye. We have chosen poly (diallyl dimethyl ammonium chloride) (PDADMAC), bio polymer as template to generate mesoporosity in the zeolite system. The samples were characterized by Fourier-transform infrared spectroscopy, scanning electron microscopy, transmission electron microscopy, X-ray diffraction, $\mathrm{N}_{2}$ adsorption analysis, thermogravimetric and ${ }^{27} \mathrm{Al} \mathrm{NMR}$. The 
influence of different parameters such initial dye concentration, zeolite dosage, contact time, $\mathrm{pH}$ and temperature was investigated. The adsorption isotherm and kinetics of adsorption is also discussed.

\section{Experimental section}

\subsection{Materials}

Poly (diallyl dimethyl ammonium chloride) solution [(PDADMAC); average $\mathrm{M}_{\mathrm{w}}$ 200,000$350,000)]$, tetrapropyl ammonium hydroxide $\left[\left(\mathrm{CH}_{3} \mathrm{CH}_{2} \mathrm{CH}_{2}\right)_{4} \mathrm{NOH} ; \mathrm{TPAOH}\right]$, tetraethyl orthosilicate $\left(\mathrm{C}_{8} \mathrm{H}_{20} \mathrm{O}_{4} \mathrm{Si}\right.$; TEOS $)$ and aluminium isopropoxide $\left(\mathrm{C}_{9} \mathrm{H}_{21} \mathrm{AlO}_{3} ;\right.$ AIP $)$ were purchased from Sigma Aldrich Co. Ltd (India). Methylene blue ((MB, $\left.\mathrm{C}_{16} \mathrm{H}_{18} \mathrm{ClN}_{3} \mathrm{~S}\right)$ used were procured from Merck, and were used without further purification.

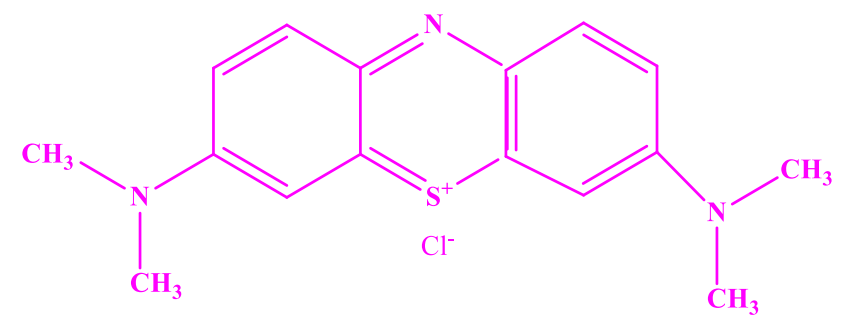

Figure 1. Structural formula of methylene blue dye.

\subsection{Synthesis of hierarchical zeolite}

The modified ZSM-5 zeolite was synthesized by employing hydrothermal crystallisation route. In a typical procedure, TEOS (3.46 g) and AIP (0.03 g) were mixed with stirring (300 rpm) to obtain a clear solution. To this, TPAOH $(2.11 \mathrm{~g})$ and PDADMAC $(0.2 \mathrm{~g})$ in aqueous solution was added and stirred for a whole day with controlled stirring (300 rpm), followed by rotavaporisation at $80^{\circ} \mathrm{C}$ for $20 \mathrm{~min}$. The transparent sticky solution thus obtained is transferred into autoclave and kept at $180^{\circ} \mathrm{C}$ for $24 \mathrm{~h}$. The synthesized zeolite was filtered, washed with water and later dried at $100^{\circ} \mathrm{C}$. Finally, the product was calcined in a muffle furnace at $550^{\circ} \mathrm{C}$ for $5 \mathrm{~h}$ to remove the meso and micro templates from the framework. The PDADMAC modified ZSM-5 zeolite so obtained has been designated as PZSM-5. For comparison studies, we synthesized conventional ZSM-5 without adding meso template, and are denoted as ZSM-5 (Radoor, Karayil, Jayakumar, Parameswaranpillai, \& Siengchin, 2021; Radoor, Karayil, Parameswaranpillai, \& Siengchin, 2020b; Sabarish, Jasila, Aswathy, Jyotishkumar, \& Suchart, 2020; Sabarish \& Unnikrishnan, 2019, 2020). Schematic representation of micro/mesopores formation in modified ZSM-5 zeolite is shown in Scheme 1. 


\subsection{Characterization}

X-ray diffraction (XRD) patterns were obtained with a Rigaku Miniflex 2200 diffractometer using $\mathrm{CuKa}$ radiation. Scanning electron microscopic images were obtained by using a Hitachi SU6600 Variable Pressure Field Emission Scanning Electron Microscope (SEM). FT-IR spectrum was recorded in the range of $400-4000 \mathrm{~cm}^{-1}$ at room temperature using an FT-IR spectrometer (Jasco 4700). Thermogravimetric (TG) analysis of the uncalcined zeolite samples was done using a TGA (Instrument Q50) at a heating rate of $10^{\circ} \mathrm{C} / \mathrm{min}$ in nitrogen atmosphere. BET surface area and pore size distributions were measured using a Micromeritics Gemini V2380 surface area analyser. Prior to the experiment, the samples were degassed at $200^{\circ} \mathrm{C}$ under vacuum. ${ }^{27} \mathrm{Al}$ MAS NMR spectra were recorded on a Bruker Avance AV 300 spectrometer. Transmission electron microscopic images (TEM) were obtained with a JEOL JEM-2100 transmission electron microscope operated at an accelerating voltage of $200 \mathrm{kV}$.

\subsection{Adsorption experiment}

In the present work, we have compared the adsorption property of modified ZSM-5 zeolite with conventional zeolite. Adsorption studies were conducted by using $0.1 \mathrm{~g}$ of the modified/conventional zeolite in $50 \mathrm{ml}$ of $\mathrm{MB}$ solution. After regular time intervals, the $\mathrm{MB}$ solution was withdrawn and the absorbance of the solution was measured using UV-Vis spectrophotometer (Shimduzu 2500) at $\lambda_{\max }$ of $665 \mathrm{~nm}$. The amount of MB adsorbed on the zeolite is calculated by the following equations.

$$
\begin{gathered}
\frac{q=\left(C_{o}-C_{e}\right) V}{W} \\
R(\%)=\frac{C_{0}-C_{e}}{C_{0}} \times 100
\end{gathered}
$$

where, $\mathrm{C}_{0}$ is the initial $\mathrm{MB}$ concentration in liquid $\left(\mathrm{mg} \mathrm{L}^{-1}\right), \mathrm{C}_{\mathrm{e}}$ is the equilibrium $\mathrm{MB}$ concentration in liquid $\left(\mathrm{mg} \mathrm{L}^{-1}\right), \mathrm{V}$ is the volume of $\mathrm{MB}(\mathrm{L})$ and $\mathrm{W}$ is weight $(\mathrm{g})$ of the zeolite. The effect of adsorption parameters such as initial MB concentration, zeolite dosage, contact time, $\mathrm{pH}$ and temperature, were also investigated and is discussed in Section 3.1

\subsection{Regeneration of adsorbents}

An adsorbent with good regeneration capacity is always preferred for practical applications. Here we checked the regeneration ability of the modified zeolite for six recycle runs. For recycling, the dye adsorbed zeolite was soaked in $\mathrm{HCl}$ : ethanol mixture for few hours, washed 

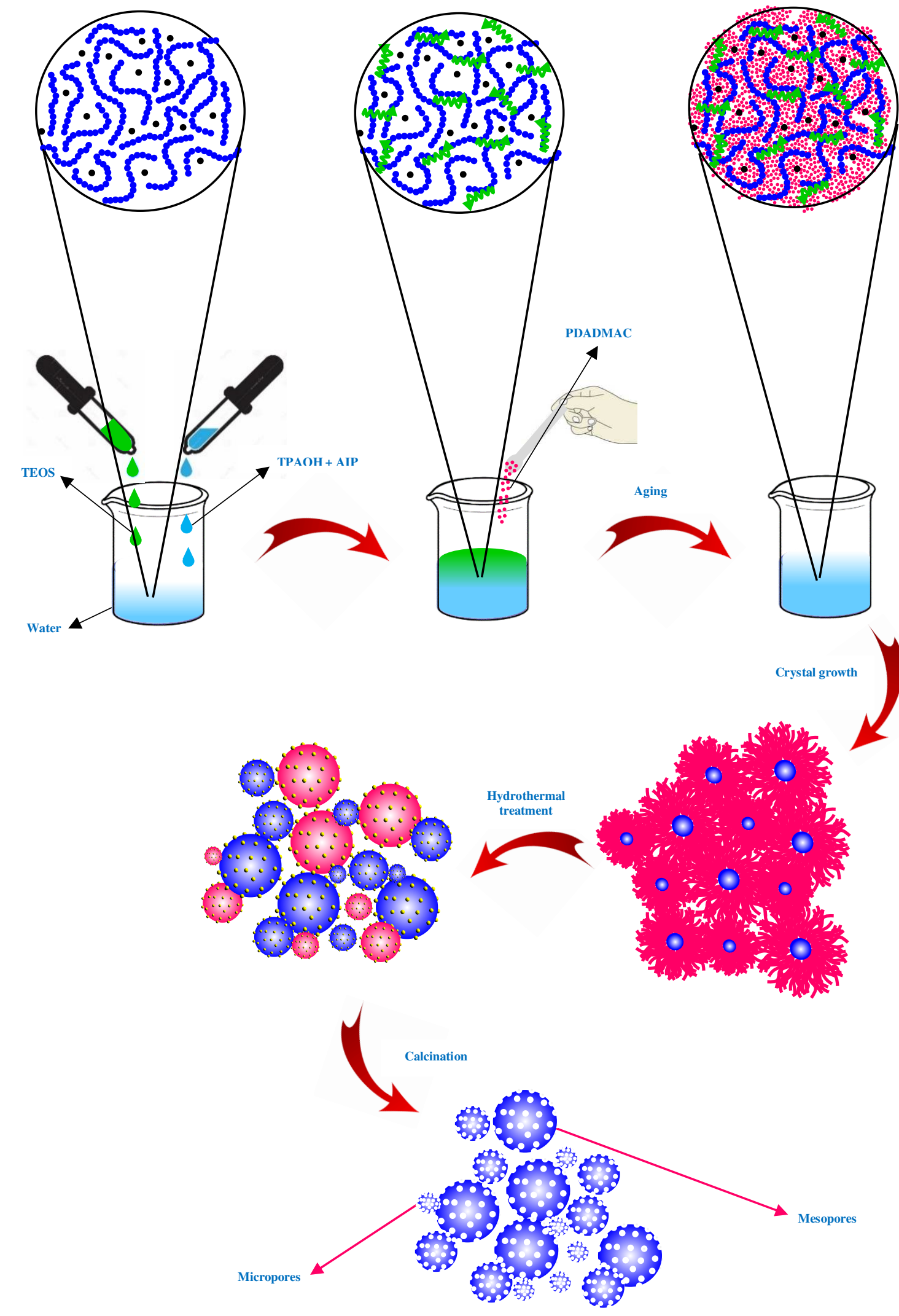

Scheme 1. Formation of micro/mesopores in modified ZSM-5 zeolite 


\section{Result and discussion}

Fourier-transform infrared spectra of conventional ZSM-5 and PDADMAC modified ZSM-5 zeolite are illustrated in Figure 2 (I). A broad absorption peak appeared at $3800-3400 \mathrm{~cm}^{-1}$ is due to $\mathrm{Si}-\mathrm{OH}$ and $\mathrm{Al}-\mathrm{OH}$ groups in zeolite. In addition to this, we can also observe distinct peaks at $1225 \mathrm{~cm}^{-1}$ (external asymmetric stretch), $1100-1050 \mathrm{~cm}^{-1}$ (internal asymmetric stretching), $795 \mathrm{~cm}^{-1}$ (external symmetric stretching), $549 \mathrm{~cm}^{-1}$ (asymmetric stretching of double five-membered ring of MFI-type zeolites) and $450 \mathrm{~cm}^{-1}$ (internal tetrahedral bending) (Narayanan et al., 2016). It is evident from Figure 2(1) that the spectra of conventional and PDADMAC modified ZSM-5 zeolite is identical and indicates the successful formation of MFI framework. The FTIR result also indicate that the added template (PDADMAC) does not distort the characteristic MFI structure of zeolite (Bai et al., 2015). The XRD diffraction pattern of conventional and PDADMAC modified ZSM-5 are displayed in Figure 2(II). It can be clearly seen that both samples displayed characteristic peak at $2 \theta=7.98^{\circ}, 8.82^{\circ}, 14.82^{\circ}, 23.14^{\circ}$, $23.96^{\circ}$ and $24.44^{\circ}$ attributed to the reflection from.[011], [020], [031], [051], [303] and [313] plane of zeolites (Narayanan, Vijaya, Sivasanker, Yang, \& Kennedy, 2014). Absence of new diffraction peaks in PDADMAC modified ZSM-5 samples confirm the successful development of MFI structure in the sample. However, the crystallinity of PDADMAC modified zeolites is found to diminish slightly probably due to the disruption of the order structure of zeolite by PDADMAC or due to the presence of mesopores in the system (Noor, Khanmohammadi, Roozbehani, Yaripour, \& Bagheri Garmarudi, 2018). This result where in accordance with previous studies where the authors report a decline in intensity with the addition of templates (Brião, Jahn, Foletto, \& Dotto, 2017). Low crystallinity in the zeolite structure is advantageous for large molecular reactions as it improves the pore connectivity and facilitates the diffusion of large molecules.

(1) 

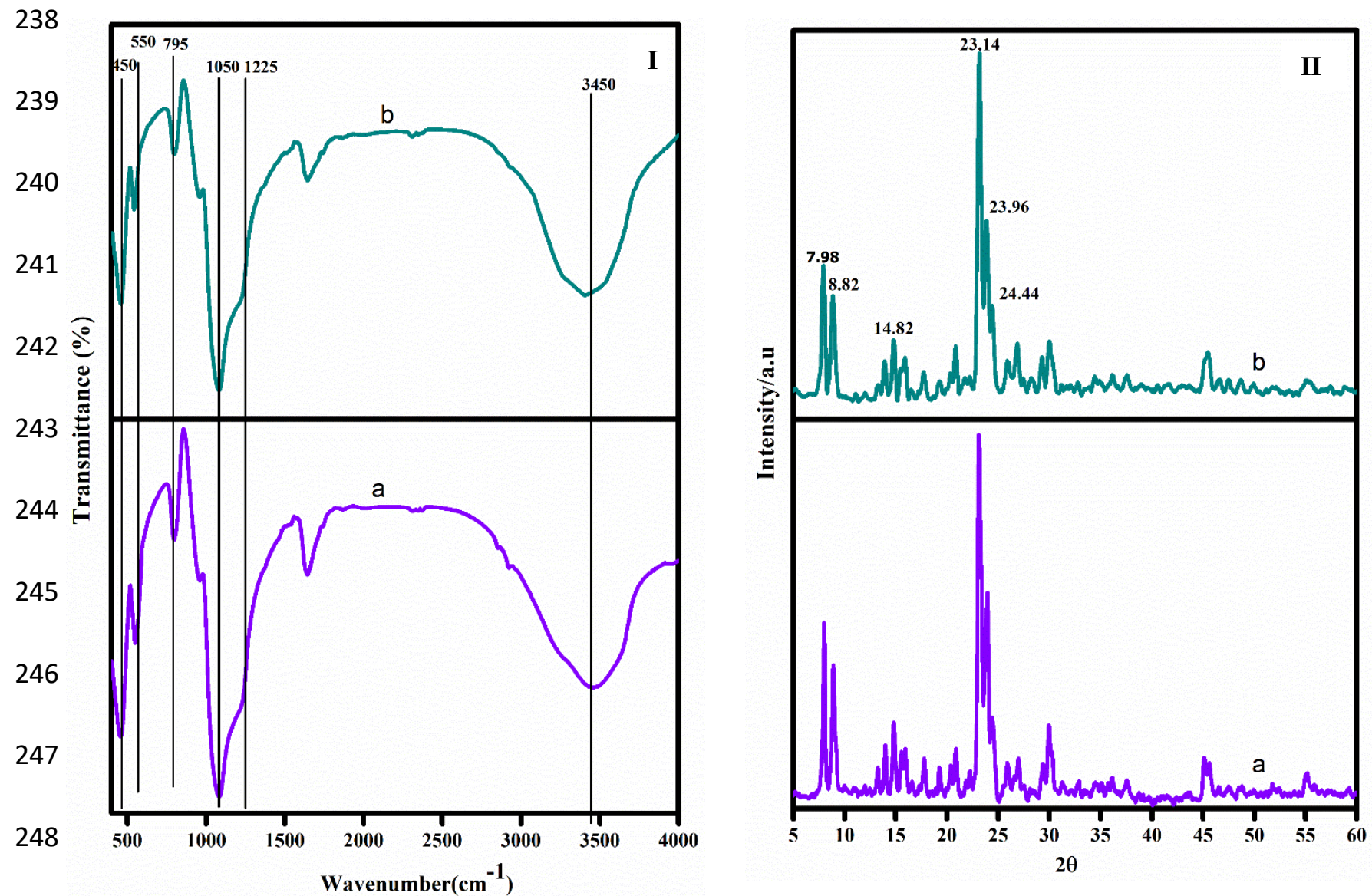

249

Figure 2. I) FTIR spectra and II) XRD pattern of a) CZSM-5 b) PZSM-5

250

The micro/meso structure of zeolite were analysed by SEM and TEM analysis. Figure 3 show the SEM images of conventional and PDADMAC modified ZSM-5. Conventional ZSM-5 displayed uniform surface with micropores while a rough surface with non-uniform distribution of micro/mesoporosity is clearly visible in the SEM micrograph of PDADMAC modified zeolite. TEM images is complimentary to SEM results and supports the formation of mesopores in PDADMAC modified zeolite. A well-defined lattice fringes seen in the SAEDD pattern of PDADMAC modified samples implies good crystallinity (Figure 4) (Tao, Li, Ren, Wang, \& Lu, 2011). The thermogravimetric curves of conventional and PDADMAC modified ZSM-5 are shown in Figure 5. Conventional ZSM-5 zeolite shows two thermal degradation at 100 and $360^{\circ} \mathrm{C}$, corresponding to the loss of water and structure directing agent (TPAOH) respectively. However, in the case of PDADMAC modified zeolite an additional weight loss at $290^{\circ} \mathrm{C}$ is also observed. This is attributed to the loss of mesotemplate (PDADMAC) from the system. The high weight loss of PDADMAC modified ZSM-5 (42\%) hint towards the presence of large pores in the modified sample (Yin et al., 2014). Figure 6 illustrated the $\mathrm{N}_{2}$ adsorption-desorption isotherm of conventional and PDADMAC modified ZSM-5 zeolite and their corresponding pore size distribution (inset of Figure 6(II)). As can be seen from Figure 6, 
266

267

268

269

270

271

272

273

274

275

276

277

278

279

280

281

282

283

284

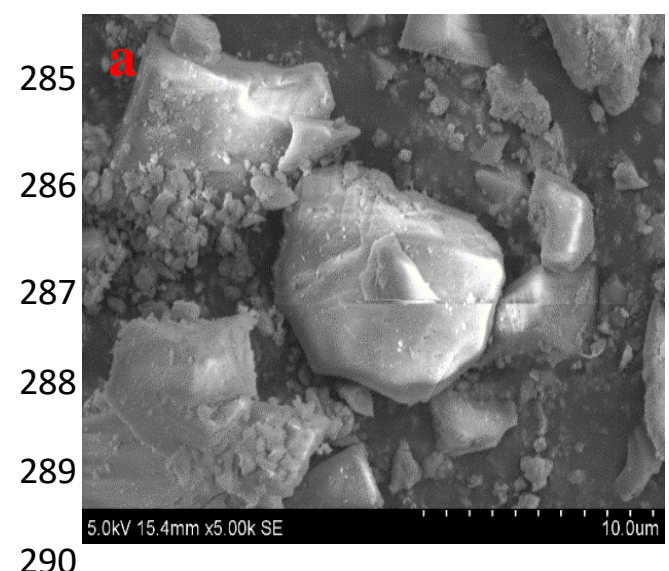

290

291

292

293

294

the conventional ZSM-5 exhibits type-I isotherm (Langmuir isotherm) without any hysteresis loop implying the microporous structure. On contrary, we can observe type-IV isotherm with a broad hysteresis loop at a relative pressure (P/P $)$ of 0.5-0.9 for PDADMAC modified ZSM5 zeolite. This is attributed to capillary condensation of nitrogen and is characteristic of mesoporous systems. BJH pore size distribution of PDADMAC modified ZSM-5 revealed a prominent curve in the range of 10-30 nm, confirming the development of micro and mesopores in the system. The additional mesopores in the PDADMAC modified ZSM-5 is due to the removal of PDADMAC from the zeolite framework. The surface area and mesopore volume of conventional and hierarchical zeolite is displayed in table 1. It can be seen that the PDADMAC templated sample possess high surface area and mesopore volume than conventional zeolite $\left(440 \mathrm{~m}^{2} / \mathrm{g}\right.$ and $\left.0.44 \mathrm{~cm}^{3} / \mathrm{g}\right)$, respectively, which were much larger than those of other ZSM-5 catalysts (Table 1). Therefore, PDADMAC modified zeolite has high pore volume than conventional ZSM-5 thus suggesting a superior adsorption power for the system. ${ }^{27} \mathrm{Al}$ NMR spectra for PDADMAC modified ZSM-5 zeolites are shown in Figure 7. We can observe two distinct signals: one at chemical shifts of $\sim 54 \mathrm{ppm}$ and the second at $\sim 0 \mathrm{ppm}$.

The peak observed at $\sim 54 \mathrm{ppm}$ and $\sim 0 \mathrm{ppm}$ corresponds to the tetrahedral and octahedral aluminium in the framework of zeolite. The ${ }^{27} \mathrm{Al}$ NMR analysis thus confirms that most of the $\mathrm{Al}$ species are tetrahedrally and octahedrally coordinated in the framework (Ma et al., 2013).

Figure 3. SEM images of a) CZSM-5 (b \& c) PZSM-5
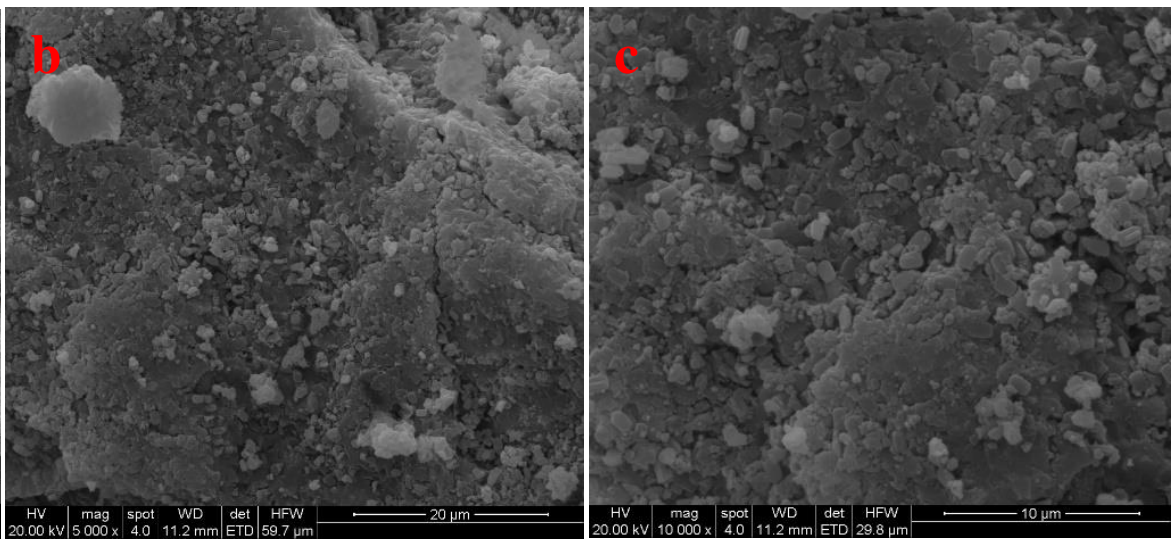


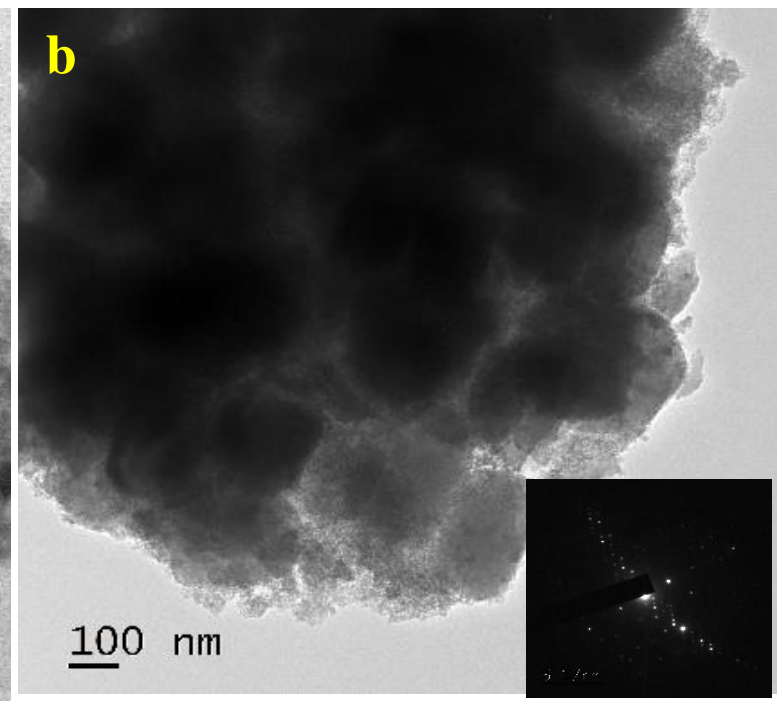

Figure 4. TEM images of PZSM-5

305
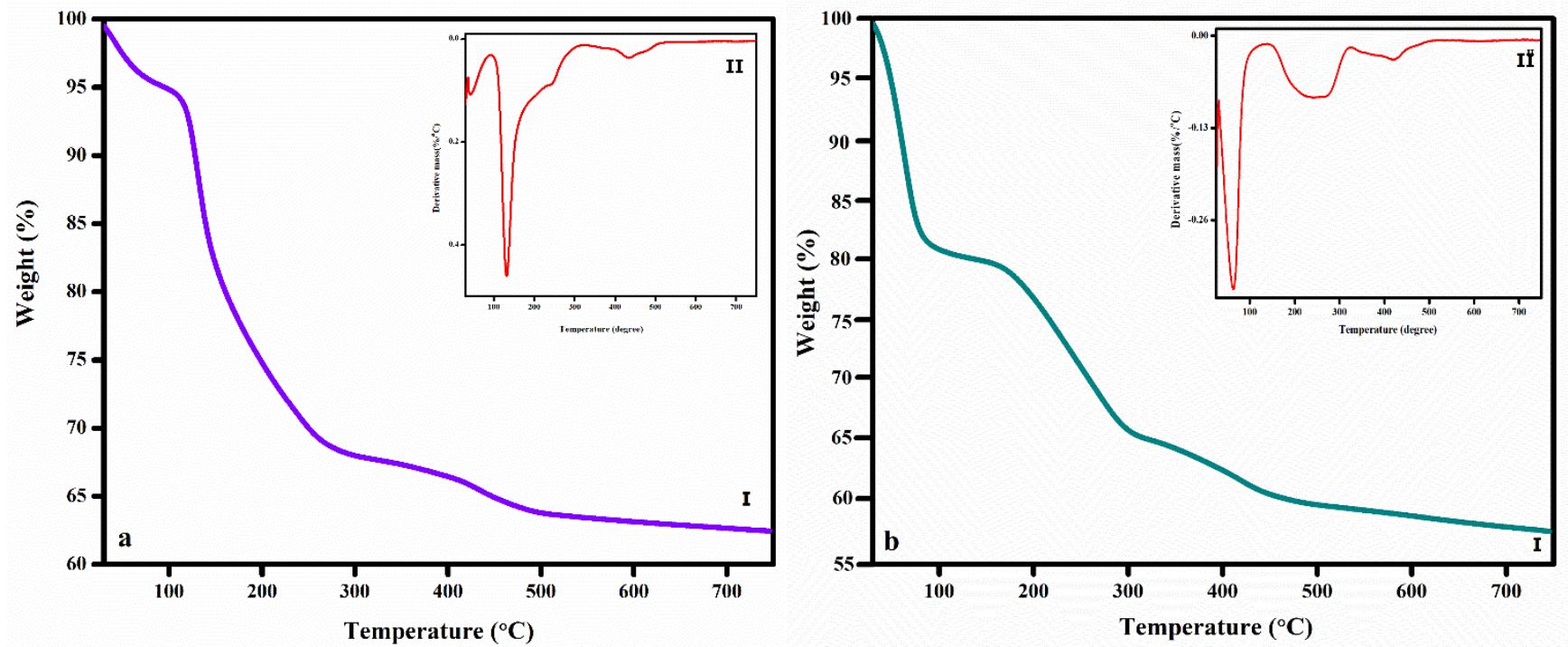

306 Figure 5. Thermogravimetric curve of: a) CZSM-5 b) PZSM-5 (DTG curves are given at the 307 inset)

308

Table .1 Textural characteristics of conventional and PDADMAC modified ZSM-5 zeolite

\begin{tabular}{cccc}
\hline Sample & $S_{\text {BET }}\left(\mathrm{m}^{2} \mathrm{~g}^{-1}\right)$ & $V_{\text {total }}\left(\mathrm{cm}^{3} \mathrm{~g}^{-1}\right)$ & $V_{\text {meso }}\left(\mathrm{cm}^{3} \mathrm{~g}^{-1}\right)$ \\
\hline PZSM-5 & 440 & 0.44 & 0.31 \\
CZSM-5 & 344 & 0.37 & 0.083 \\
\hline
\end{tabular}



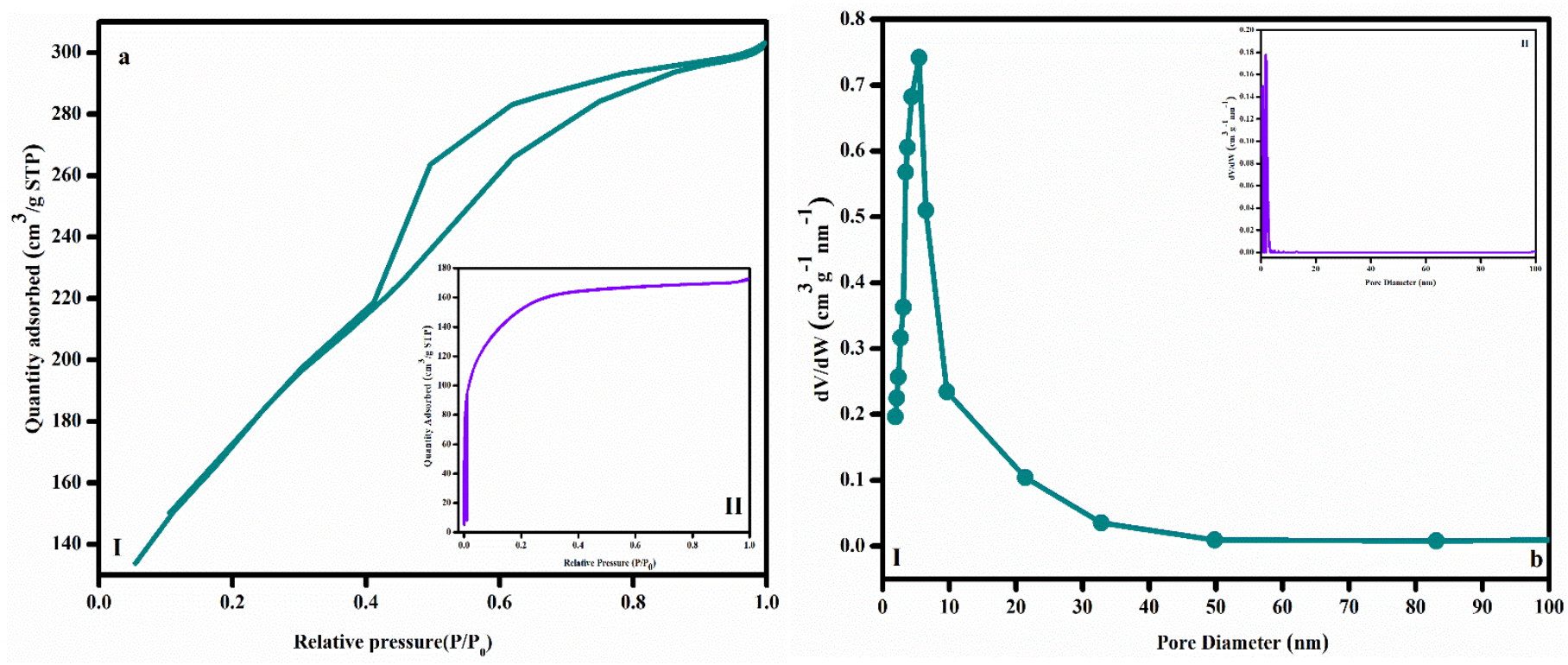

Figure 6. (a) Nitrogen adsorption-desorption isotherms of (i) PZSM-5 (ii) (inset) CZSM-5; (b) Pore size distribution curve of: (i) PZSM-5 (ii) (inset) CZSM-5

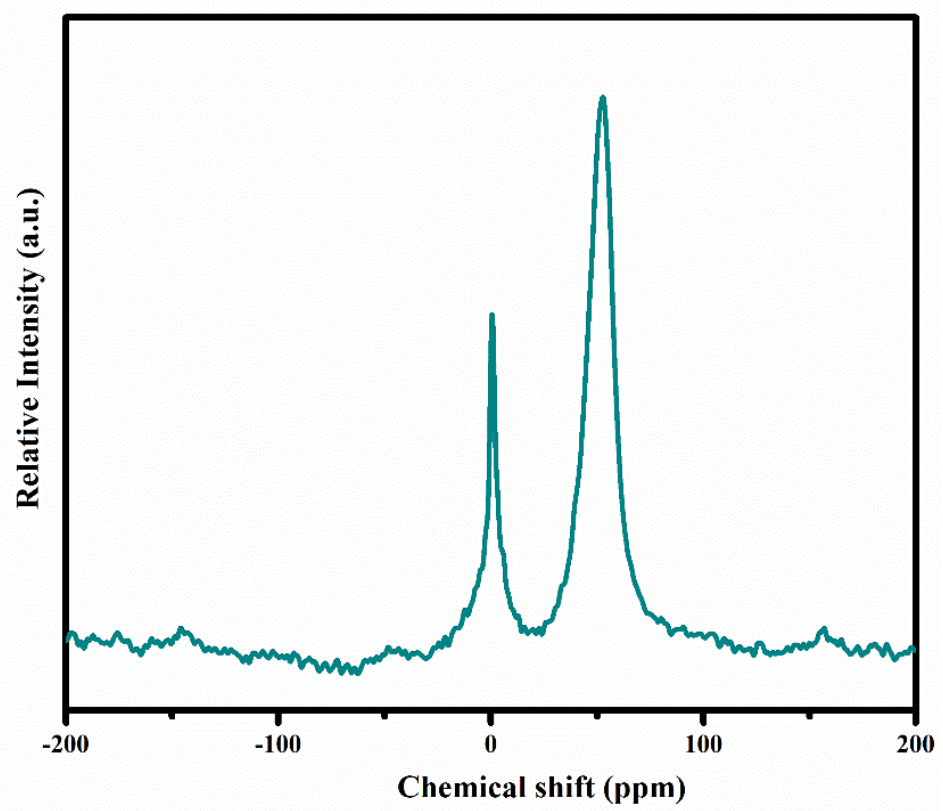

Figure 7. Solid state ${ }^{27}$ AINMR spectra of PZSM-5

\subsection{Adsorption studies}

326 An idea of optimum adsorbent dosage is essential for large scale industrial applications. So, we

327 have varied the zeolite dosage from 0.025 to $0.1 \mathrm{~g}$ by keeping other parameters constant. The

328 effect of zeolite dosage on the adsorption of MB is graphically depicted in Figure 8 (a). From the figure, one can see that on increasing the zeolite amount from 0.025 to $0.1 \mathrm{~g}$, the adsorption capacity increases from 2.9 to $4.31 \mathrm{mg} / \mathrm{g}$. This could be due to enhancement in the total surface 
area of the system which promotes the adherence of MB on the surface of zeolite. Since PDADMAC modified zeolite contain mesopores, an enhancement in its dosage could have increase the number of mesopores in the system and thus facilitates the penetration of large MB molecules (Stavrinou, Aggelopoulos, \& Tsakiroglou, 2018). The effect of contact time for the uptake of MB by modified zeolite was examined and the result is illustrated in Figure 8 (b). It is evident that the adsorption take place in two stage. In the first stage, the adsorption capacity increases rapidly with contact time, probably due to the availability of large number of active sites. Meanwhile, in the second stage, only a slow increase in the adsorption capacity with contact time was observed and after $4 \mathrm{~h}$ the adsorption attains equilibrium. This may be allocated to the fact that the number of available adsorption site on the surface of zeolite decreases with contact time and eventually all adsorption sites will be occupied by $\mathrm{MB}$ molecule. Therefore, all experiments were conducted at a contact time of $4 \mathrm{~h}$. In order to evaluate the effect of initial concentration of MB on modified ZSM-5 we have varied the initial concentration from 10 to $50 \mathrm{ppm}$. It is revealed that adsorption capacity increases with initial dye concentration but the removal percentage decreases. On increasing MB concentration, the mass driving force for the transfer of MB from solid to liquid phase increases and thus leads to enhancement in the adsorption capacity. The reduction in the removal percentage could be due to the decline in the ratio of number of available adsorption site to the number of MB molecules (Figure 8 (c)). This trend is in agreement with previous reports (Eltaweil, Ali Mohamed, Abd El-Monaem, \& El-Subruiti, 2020). $\mathrm{pH}$ is an important factor that influence the adsorption process, so in this present work, adsorption of MB dye on zeolite have been studied at different $\mathrm{pH}(2-10)$ and is displayed in Figure 8 (d). At low $\mathrm{pH}$, due to the possible protonation, the surface of adsorbent becomes positive charged and thus repel the incoming MB molecule. However, at high $\mathrm{pH}$, the surface becomes negative and thus provide a favourable condition (electrostatic attraction) for the attachment of MB molecule on surface of zeolite. From the above studies, it can be concluded that low $\mathrm{pH}$ disfavours the adsorption of MB on zeolite while high $\mathrm{pH}$ favours the adsorption process. Finally, we monitored the adsorption capacity as a function of temperature and is displayed shown in Figure 8 (e). It is clear from Figure 8 (e) that upon increasing the temperature the adsorption capacity slightly increases, implying an endothermic nature of the adsorption process. Another plausible reason is that thermal energy provides a favourable driving force for the diffusion of large MB molecule from liquid solution into the solid adsorbent. 
365 Figure 9 illustrates the comparison of adsorption performance of PDADMAC modified ZSM366 5zeolite with conventional ZSM-5zeolite. It can be seen that PDADMAC modified zeolite 367 exhibits high adsorption capacity than conventional zeolite, probably due to the difference in 368 the porosity, which is evident from morphological and BET analysis. In the case of conventional zeolite, only surface adsorption is possible, as the small micropores in it will restrict the penetration of large MB molecules. However, mesopores in PDADMAC modified zeolite facilitates the penetration of large MB molecules and thus offer a higher adsorption capacity than conventional zeolite.

\section{Reusability}

An adsorbent with good regeneration ability is always recommended for the treatment of water treatment. In the present work, the regeneration capacity of PDADMAC modified zeolite was checked for six adsorption-desorption cycle. From figure 9 it is clear that the adsorption capacity of zeolite slightly reduced with number of cycles. Nevertheless, even after 6 recycle it possess good removal efficiency thus suggesting it as a potential candidate for dye removal application.
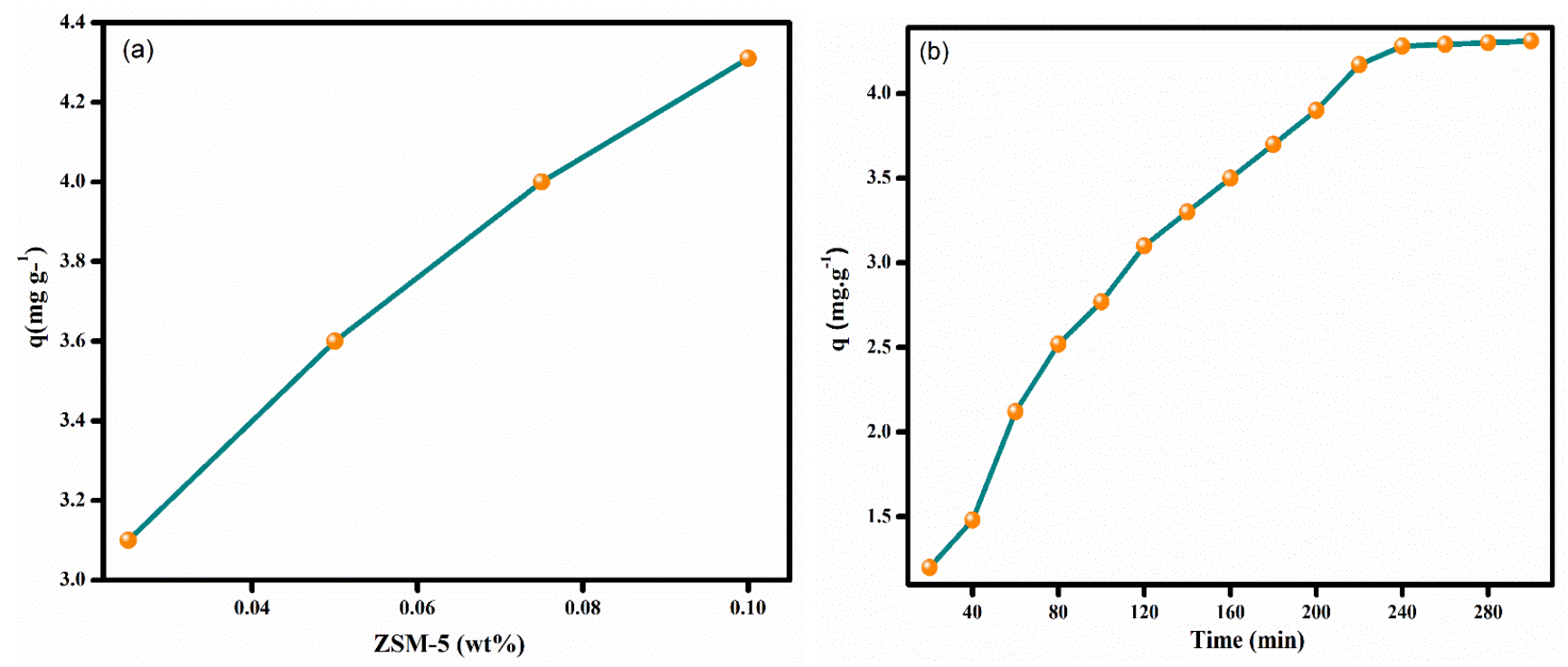

380 

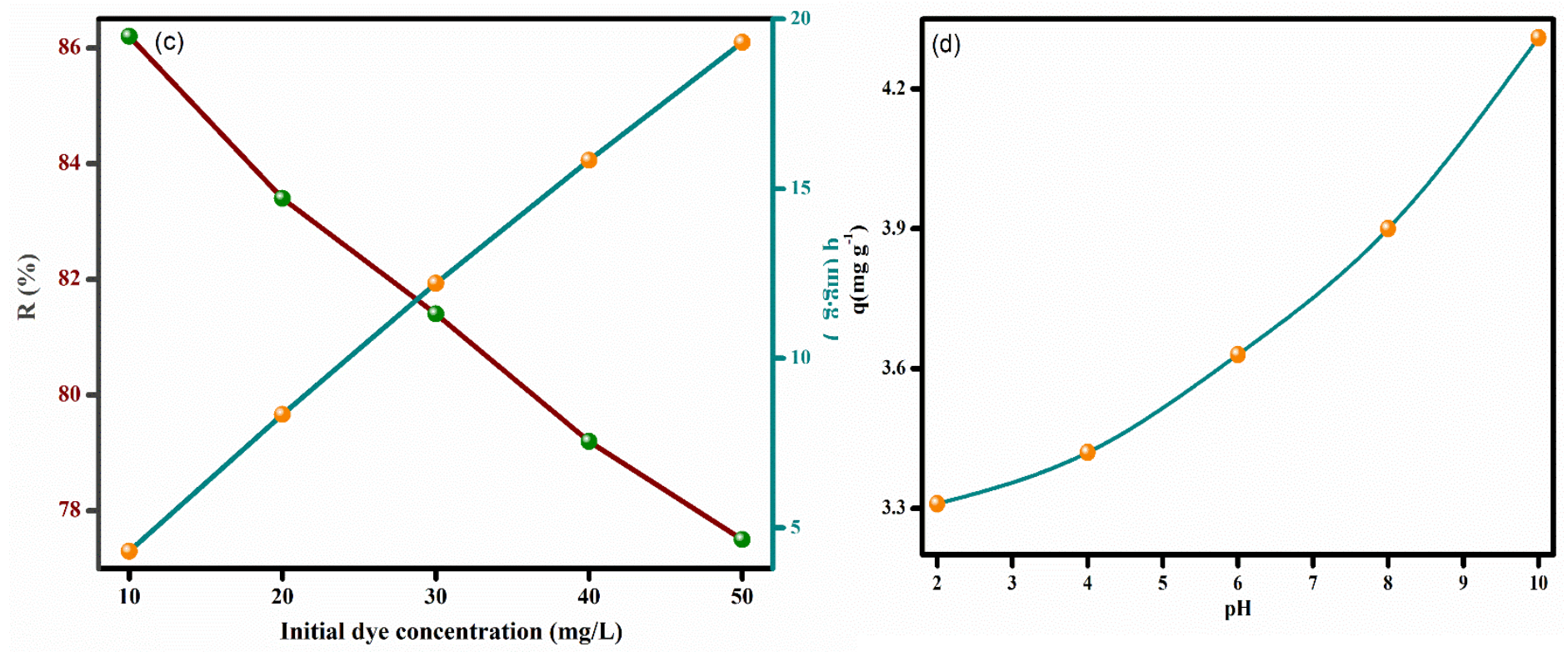

sys

394

395

396

397

398

399

400

401

402

403

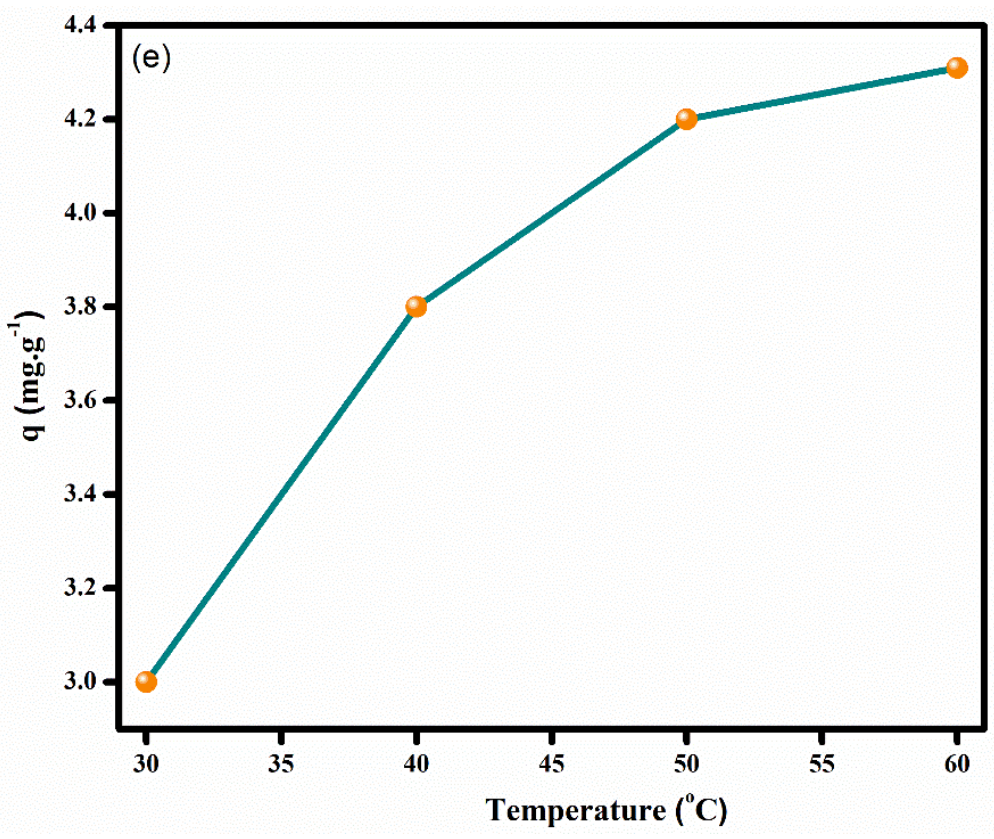

404

405 Figure 8. Effect of different parameters a) zeolite dosage; b) contact time; c) initial dye 406 concentration; d) $\mathrm{pH}$; e) temperature on adsorption of MB on PDADMAC modified ZSM-5 

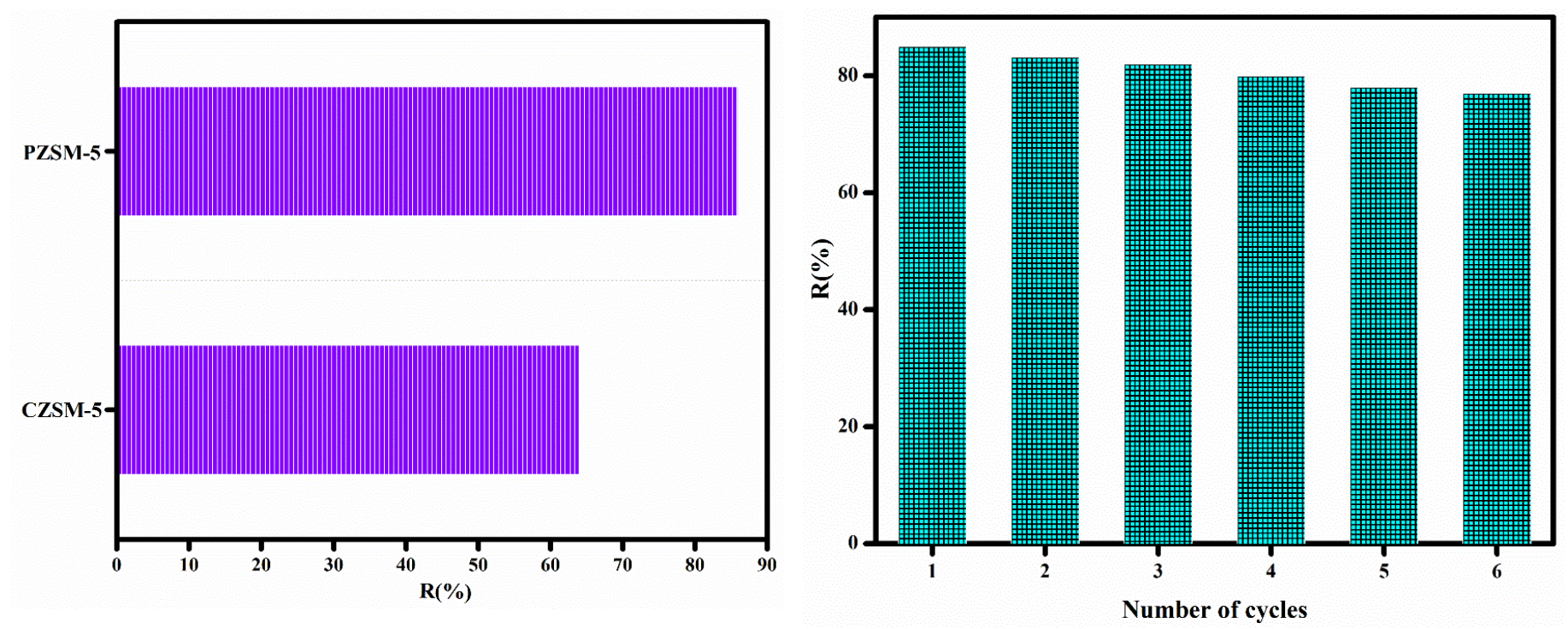

407

408 Figure 9. Effect of different type of zeolite and reusability of MB dye on PDADMAC modified 409 ZSM-5

410

\section{Adsorption kinetics}

412 Kinetic models were employed to understand the rate and mechanism of adsorption. In the 413 present study, the kinetics of MB adsorption onto PDADMAC modified zeolite was evaluated 414 by applying pseudo-first-order (PFO) and pseudo-second-order (PSO) model. The differential 415 form of pseudo-first-order model is represented as

$$
\frac{d q_{t}}{d t}=K_{1}\left(q_{e}-q_{t}\right)
$$

417 Where $\mathrm{q}_{\mathrm{t}}(\mathrm{mg} / \mathrm{g})$ is the amount of MB adsorbate on the surface of PDADMAC modified zeolite at time $\mathrm{t}, \mathrm{q}_{\mathrm{e}}$ is the equilibrium adsorption capacity $(\mathrm{mg} / \mathrm{g}) . \mathrm{K}_{1}$ is pseudo-first-order rate constant $\left(\mathrm{L} \mathrm{min}{ }^{-1}\right)$. The linearized form of equation 3 is represented as

$$
\log \left(q_{e}-q_{t}\right)=\log q_{e}-\frac{K_{1} t}{2.303}
$$

421 The kinetic parameter $\mathrm{K}_{1}$ and $\mathrm{q}_{\mathrm{e}}$ were obtained from the linear fit of $\log \left(\mathrm{q}_{\mathrm{e}}-\mathrm{q}_{\mathrm{t}}\right)$ against time

422 The PSO model is represented as

$$
\frac{d q_{t}}{d t}=K_{1}\left(q_{e}-q_{t}\right)^{2}
$$

425 The equation (5) is integrated by applying boundary condition and on rearranging gives the 426 linearized form which is represented as follows 
428 Where $\mathrm{K}_{2}$ is the rate constant of PSO ( $\mathrm{g} / \mathrm{mg}$ min). The value of $\mathrm{q}_{\mathrm{e}}$ and $\mathrm{K}_{2}$ can be calculated from the linear plot of t/qt vs time.
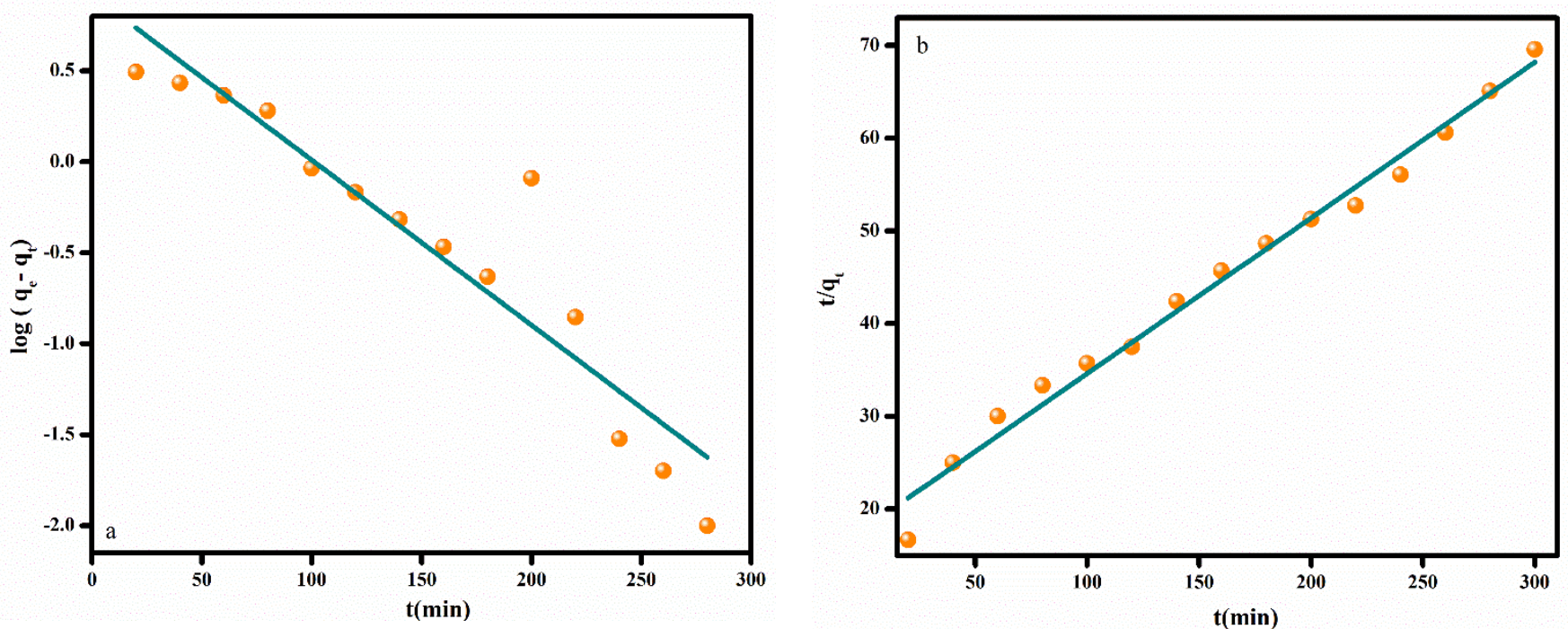

430 Figure 10. Linear kinetic plots of a) pseudo-first-order b) pseudo-second-order models for the 431 adsorption of MB dye for the PDADMAC modified ZSM-5 zeolite

432 The goodness of fit (correlation coefficient $\mathrm{R}^{2}$ ) is used to identify the best kinetic model for 433 adsorption process. Kinetic model with high correlation coefficient $\left(\mathrm{R}^{2}\right)$ value is usually 434 selected as the best model for a particular adsorption reaction (Sartape et al., 2017; Sharma, 435 Kaur, Baskar, \& Chung, 2010). In order to identify the kinetic model, we have fitted the 436 experimental data into PFO and PSO. The linear fitted graph is shown in Figure 10 and the 437 kinetic parameters are summarized in Table 2. On comparing the linear plot and $\mathrm{R}^{2}$, one can 438 observe that PSO model has best agreement with the experimental adsorption data and is most 439 suitable to describe MB adsorption on zeolite.

440 Table 2. Adsorption kinetic parameters and correlation coefficient for the adsorption of MB 441 dye on modified ZSM-5 zeolite with PFO and PSO

\begin{tabular}{|c|c|c|c|c|c|c|}
\hline \multirow{2}{*}{$\begin{array}{c}\operatorname{Exp} \\
q_{e}, \exp \left(m g g^{-1}\right)\end{array}$} & \multicolumn{3}{|c|}{ Pseudo-first-order } & \multicolumn{3}{|c|}{ Pseudo-second-order } \\
\hline & $K_{I}$ & $q_{e}\left(m g g^{-1}\right)$ & $R^{2}$ & $K_{2}\left(g^{m g^{-1}} \min ^{-1}\right)$ & $q_{e}\left(m g g^{-1}\right)$ & $R^{2}$ \\
\hline 4.31 & -0.0218 & 10 & 0.93 & 0.00157 & 4.8 & 0.999 \\
\hline
\end{tabular}


445 Adsorption isotherm describes the interaction between adsorbent and adsorbate and elucidates 446 the adsorption mechanism. The experiment data of MB on PDADMAC modified ZSM-5 447 zeolite was analysed using two well-known models; Langmuir and Freundlich isotherms.

448 The Langmuir isotherm assumes an equivalent adsorption site on the surface of adsorbent and neglects any interaction between the adsorbed molecules. Thus, it suggests monolayer formation on the surface of the adsorbent. The linear form of Langmuir equation can be described as

$$
\frac{\mathrm{C}_{\mathrm{e}}}{\mathrm{q}_{\mathrm{e}}}=\left(\frac{\mathrm{C}_{\mathrm{e}}}{\mathrm{q}_{\max }}\right)+\left(\frac{1}{\mathrm{~K}_{\mathrm{L}} * \mathrm{q}_{\max }}\right)
$$

453

Where $K_{L}$ is Langmuir constant, $C_{e}$ is equilibrium dye concentration $(\mathrm{mg} / \mathrm{L})$, $\mathrm{q}_{\mathrm{e}}$ is the amount of dye adsorbed onto the ZSM-5 (mg/g) and $\mathrm{q}_{\max }$ is maximum adsorption $(\mathrm{mg} / \mathrm{g})$. The linear plot of $C_{e} / q_{e}$ against $C_{e}$ gives a straight with slope $1 / q_{m}$ and intercept $1 / q_{m} K_{L}$. $R_{L}$ (equilibrium parameter) is another characteristic parameter obtained from Langmuir isotherm model and is used to predict the favorability of the adsorption process. The value of $R_{L}$ between 0 and 1 is considered as favorable for the adsorption process.

The Freundlich model assumes multilayer adsorption on a heterogenous surface. The linear form of Freundlich equation can be expressed as follows;

$$
\ln \left(\mathrm{q}_{\mathrm{e}}\right)=\operatorname{InK}_{\mathrm{F}}+\frac{1}{\mathrm{n}} * \operatorname{In}\left(\mathrm{C}_{\mathrm{e}}\right)
$$

where $K_{F}$ is Freundlich constant $\left.(\mathrm{mg} / \mathrm{g})(\mathrm{L} / \mathrm{mg})^{1 / \mathrm{n}}\right)$ and $\mathrm{n}$ is the heterogeneity factor. $\mathrm{K}_{\mathrm{F}}$ is related to the adsorption capacity and ' $n$ ' indicates the feasibility of adsorption. Adsorption process is considered to be favorable if the value of $1 / \mathrm{n}$ is between 0 and 1 (Sabarish \& Unnikrishnan, 2018a, 2018b, 2018c; Vadivelan \& Kumar, 2005).

\section{Comparison with other adsorbent}

From the Table 3, it is clear that the hierarchical ZSM-5 possess fairly good adsorption capacity and its comparable with other adsorbents. Hence, PDADMAC modified ZSM-5 zeolite could be a promising candidate for the removal of $M B$ from aqueous solutions. 


\begin{tabular}{lcc}
\hline Adsorbents & $\begin{array}{c}\boldsymbol{q}_{\max } \\
(\mathbf{m g} / \mathbf{g})\end{array}$ & References \\
\hline Graphite oxide & 0.74 & (Gong et al., 2015) \\
Cotton alk & 0.024 & (Ding, Hu, Zimmerman, \& Gao, 2014) \\
Coalfly ash & 2.88 & (X. Jin et al., 2008) \\
$\begin{array}{l}\text { Acid-activated milled } \\
\text { pyrophylite }\end{array}$ & 4.2 & (Golubeva \& Pavlova, 2016) \\
$\begin{array}{l}\text { Perlite } \\
\text { AC-apricot shell }\end{array}$ & 0.7 & (Acemioglu, 2005) \\
PDADMAC modified zeolite & 4.11 & This work -Karaks, \& Duman, 2003) \\
\hline
\end{tabular}

472
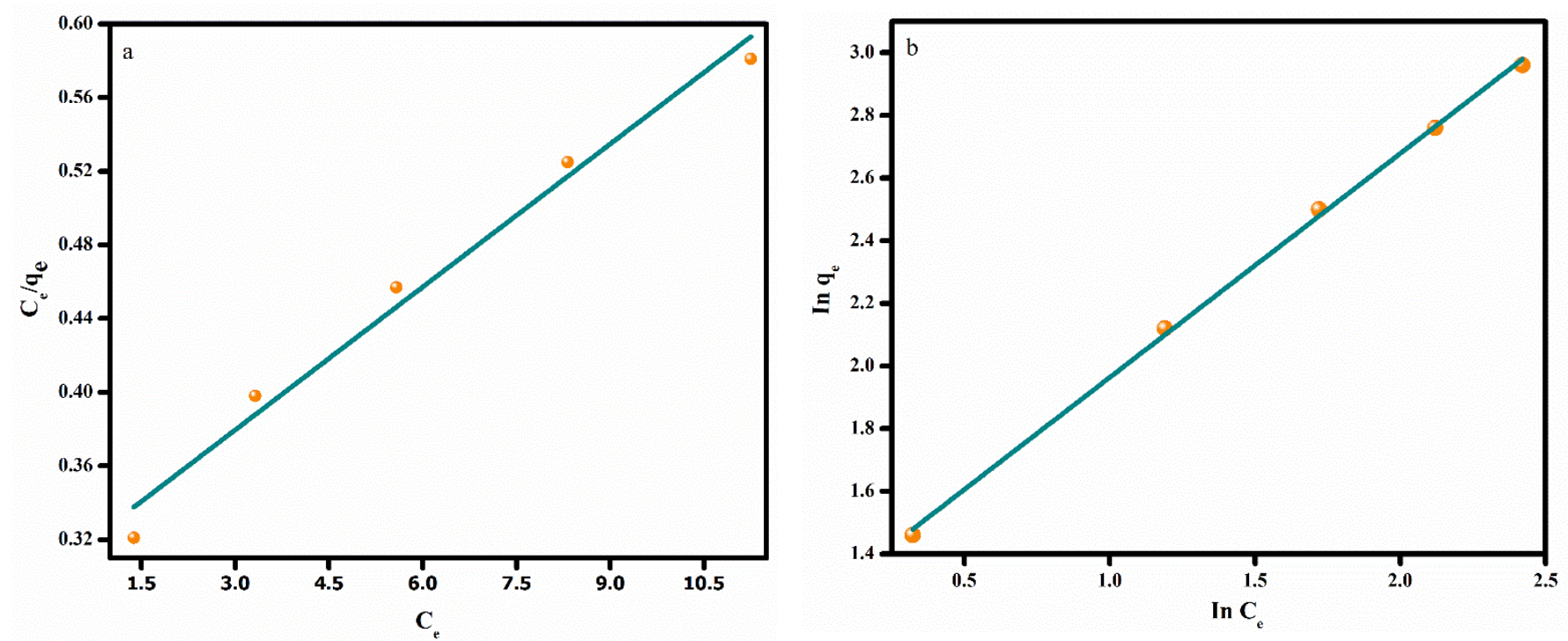

473

478 The plot of $\ln \mathrm{q}_{\mathrm{e}}$ versus $\ln \mathrm{C}_{\mathrm{e}}$ and $\mathrm{C}_{\mathrm{e}} / \mathrm{qe}$ versus $\mathrm{C}_{\mathrm{e}}$ for $\mathrm{MB}$ adsorption on PDADMAC modified

Figure 11. Linear isotherm plots of a) Langmuir b) Freundlich model for the adsorption of MB dye for the PDADMAC modified ZSM-5 zeolite

Table 4. Adsorption isotherm parameters and correlation coefficient for the adsorption of MB dye on modified ZSM-5 zeolite with Langmuir and Freundlich

\begin{tabular}{ccccccc}
\hline Exp & \multicolumn{3}{c}{ Langmuir isotherm } & \multicolumn{3}{c}{ Freundlich isotherm } \\
\hline $\mathbf{q}_{\mathbf{e}}, \exp \left(\mathbf{m g ~ g}^{-1}\right)$ & $\mathbf{R}^{\mathbf{2}}$ & $\mathbf{q}_{\max }\left(\mathbf{m g ~ g}^{-1}\right)$ & $\mathbf{K}_{\mathbf{L}}$ & $\mathbf{R}^{2}$ & $\mathbf{K}_{\mathbf{F}}\left(\mathbf{m g ~ g}^{-1}\right)$ & $\mathbf{n}$ \\
\hline 4.31 & 0.98 & 38 & 0.085 & 0.999 & 3.8 & 1.4 \\
& & & & & & \\
\hline
\end{tabular}
ZSM-5 zeolite is shown in Figure 11 and the corresponding adsorption parameter are displayed in Table 4. As can be seen Figure11 the experimental data fitted well in the Freundlich model 
481 with a high regression coefficient value (0.99). The value of $1 / \mathrm{n}$ is found to be (0.714) implying 482 a favorable adsorption. Thus, MB molecules is distributed in multilayer fashion on the surface 483 of PDADMAC modified zeolite.

484

485

486

487

488

489

490

491

492

493

494

495

496

497

498

499

500 


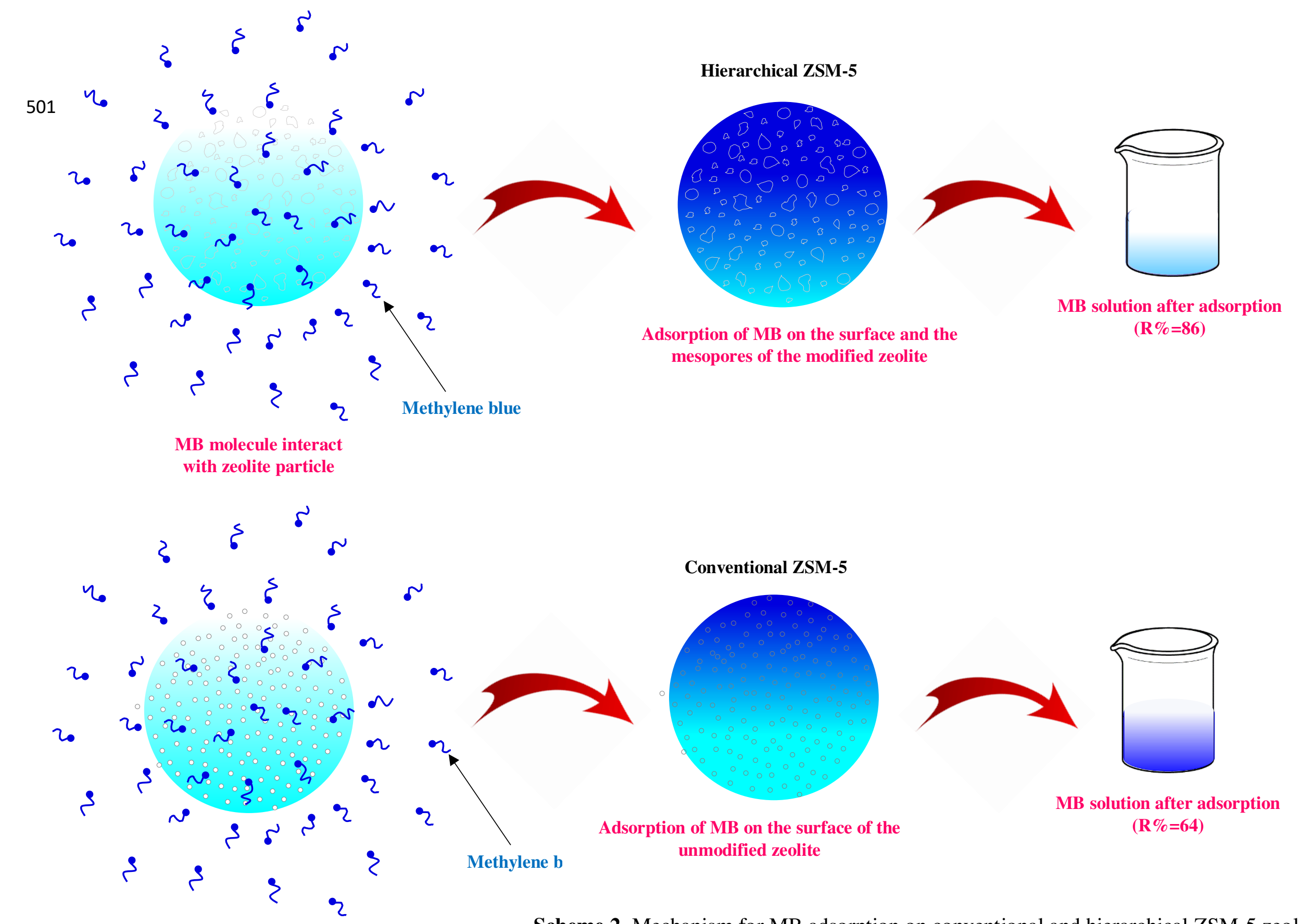

Scheme 2. Mechanism for MB adsorption on conventional and hierarchical ZSM-5 zeolite with zeolite particle 
503 A modified ZSM-5 zeolite was successfully developed by using PDADMAC as the 504 mesotemplate. The crystallinity and chemical structure of synthesised zeolite is confirmed by 505 XRD and FTIR analysis. $\mathrm{N}_{2}$ adsorption and morphological analysis confirms the generation of 506 mesopores in the PDADMAC modified samples. Adsorption studies indicate that PDADMAC modified ZSM-5 zeolite is as good adsorbent for the removal of cationic dye MB, from aqueous solution. The result further shows that adsorption process could be tuned by varying the operation parameters such as zeolite dosage, initial dye concentration, contact time, temperature and $\mathrm{pH}$. Optimized conditions for removal efficiency are as follows (modified ZSM-5 zeolite :0.1 g, initial dye concentration:10 mg/L, pH: 10 and contact time: $300 \mathrm{~min}$ ). The adsorption isotherm and kinetic studies indicate that Freundlich model and pseudo-secondorder model is the best model to explain MB adsorption onto PDADMAC modified zeolite. The recyclability results suggest that PDADMAC modified ZSM-5 zeolite possess good regeneration capacity. Thus, we propose PDADMAC modified ZSM-5 zeolite as a potential adsorbent for removing methylene blue from water. 


\section{Declarations}

\section{Ethics approval and consent to participate}

537 The article we have submitted to the journal for review is original, has been written by the 538 stated authors and has not been published elsewhere. The images that we have submitted to the 539 journal for review are original, and has not been published elsewhere. This manuscript has not 540 been submitted to, nor is under review at, another journal or other publishing venue. The 541 authors have no affiliation with any organization with a direct or indirect financial interest in 542 the subject matter discussed in the manuscript.

\section{Consent for publication}

544 The authors confirm the consent for publication

\section{Availability of data and material}

546 All data generated or analysed during this study are included in this published article

\section{Competing interests}

548 The authors don't have any conflicts of interests.

\section{Funding}

550 (Grant No. KMUTNB-63-Post-03 to SR) and (Grant No. KMUTNB-64-03, KMUTNB551 BasicR-64-16) Authors contribution Sabarish Radoor- Conceptualization, Methodology, Investigation, Validation, Writing original draft, Software, Writing - review \&editing, Formal analysis; Jasila Karayil Investigation, Analysis, Interpretation of results, Software, Writing - review \& editing, Formal analysis.; Aswathy Jayakumar - Data collection, Validation, Writing - review \& editing, Formal analysis; Jyotishkumar Parameswaranpillai -Validation, Software, Writing - review \& editing and Investigation; Suchart Siengchin - Editing, Funding and Supervision Acknowledgements

560 The authors are grateful to the King Mongkut's University of Technology North Bangkok 561 (KMUTNB), Thailand and grant funded the Post-Doctoral scholarship ((Grant No. KMUTNB63-Post-03 to SR) and (Grant No. KMUTNB-64-03, KMUTNB-BasicR-64-16)

563 For further information on what should be included under each heading, please select the 564 Instructions for Author link.

\section{Reference}

Acemioglu B. (2005). Batch kinetic study of sorption of methylene blue by perlite. Chemical Engineering Journal, 106(1): 73-81. doi:10.1016/j.cej.2004.10.005.

Adegoke K A, \& Bello O S. (2015). Dye sequestration using agricultural wastes as adsorbents. Water Resources and Industry, 12: 8-24. doi:10.1016/j.wri.2015.09.002. 
Aichour A, \& Zaghouane-Boudiaf H. (2019). Highly brilliant green removal from wastewater by mesoporous adsorbents: Kinetics, thermodynamics and equilibrium isotherm studies. Microchemical Journal, 146: 1255-1262. doi:10.1016/j.microc.2019.02.040.

Ali I. (2012). New Generation Adsorbents for Water Treatment. Chemical Reviews, 112(10): 50735091. doi:10.1021/cr300133d.

Alver E, \& Metin A Ü. (2012). Anionic dye removal from aqueous solutions using modified zeolite: Adsorption kinetics and isotherm studies. Chemical Engineering Journal, 200-202: 59-67. doi:10.1016/j.cej.2012.06.038.

Armagan B, Turan M, \& Karadag D. (2010). Adsorption of Different Reactive Dyes onto SurfactantModified Zeolite: Kinetic and Equilibrium Modeling. In Survival and Sustainability (pp. 12371254).

Armağan B, Turan M, Özdemir O, \& Çelik M S. (2004). Color Removal of Reactive Dyes from Water by Clinoptilolite. Journal of Environmental Science and Health, Part A, 39(5): 1251-1261. doi:10.1081/ese-120030329.

Aygün A, Yenisoy-Karakaş S, \& Duman I. (2003). Production of granular activated carbon from fruit stones and nutshells and evaluation of their physical, chemical and adsorption properties. Microporous and Mesoporous Materials, 66(2-3): 189-195. doi:10.1016/j.micromeso.2003.08.028.

Aysan H, Edebali S, Ozdemir C, Celik Karakaya M, \& Karakaya N. (2016). Use of chabazite, a naturally abundant zeolite, for the investigation of the adsorption kinetics and mechanism of methylene blue dye. Microporous and Mesoporous Materials, 235: 78-86. doi:10.1016/j.micromeso.2016.08.007.

Bai P, Wu P, Xing W, Liu D, Zhao L, Wang Y, . . Zhao X S. (2015). Synthesis and catalytic properties of ZSM-5 zeolite with hierarchical pores prepared in the presence of $n$ hexyltrimethylammonium bromide. Journal of Materials Chemistry A, 3(36): 18586-18597. doi:10.1039/c5ta05350a.

Benkhaya S, Achiou B, Ouammou M, Bennazha J, Alami Younssi S, M'rabet S, \& El Harfi A. (2019). Preparation of low-cost composite membrane made of polysulfone/polyetherimide ultrafiltration layer and ceramic pozzolan support for dyes removal. Materials Today Communications, 19: 212-219. doi:10.1016/j.mtcomm.2019.02.002.

Brião G V, Jahn S L, Foletto E L, \& Dotto G L. (2017). Adsorption of crystal violet dye onto a mesoporous ZSM- 5 zeolite synthetized using chitin as template. Journal of Colloid and Interface Science, 508: 313-322. doi:10.1016/j.jcis.2017.08.070.

Cao Y-L, Pan Z-H, Shi Q-X, \& Yu J-Y. (2018). Modification of chitin with high adsorption capacity for methylene blue removal. International Journal of Biological Macromolecules, 114: 392-399. doi:10.1016/j.ijbiomac.2018.03.138.

Cengiz S, \& Cavas L. (2008). Removal of methylene blue by invasive marine seaweed: Caulerpa racemosa var. cylindracea. Bioresource Technology, 99(7): 2357-2363. doi:10.1016/j.biortech.2007.05.011.

Dil E A, Ghaedi M, Ghezelbash G R, Asfaram A, Ghaedi A M, \& Mehrabi F. (2016). Modeling and optimization of $\mathrm{Hg} 2+$ ion biosorption by live yeast Yarrowia lipolytica 70562 from aqueous solutions under artificial neural network-genetic algorithm and response surface methodology: kinetic and equilibrium study. RSC Advances, 6(59): 54149-54161. doi:10.1039/c6ra11292g.

Ding Z, Hu X, Zimmerman A R, \& Gao B. (2014). Sorption and cosorption of lead (II) and methylene blue on chemically modified biomass. Bioresource Technology, 167: 569-573. doi:10.1016/j.biortech.2014.06.043.

Drumm F C, Oliveira J S d, Enders M S P, Müller E I, Urquieta-González E A, Dotto G L, . . Jahn S L. (2018). Use of chitin as a template for the preparation of mesostructured ZSM-5. Cerâmica, 64(370): 214-218. doi:10.1590/0366-69132018643702271. 
El Alouani M, Alehyen S, El Achouri M, \& Taibi M h. (2019). Comparative study of the adsorption of micropollutant contained in aqueous phase using coal fly ash and activated coal fly ash: Kinetic and isotherm studies. Chemical Data Collections, 23. doi:10.1016/j.cdc.2019.100265.

Eltaweil A S, Ali Mohamed H, Abd El-Monaem E M, \& El-Subruiti G M. (2020). Mesoporous magnetic biochar composite for enhanced adsorption of malachite green dye: Characterization, adsorption kinetics, thermodynamics and isotherms. Advanced Powder Technology, 31(3): 1253-1263. doi:10.1016/j.apt.2020.01.005.

Golubeva O Y, \& Pavlova S V. (2016). Adsorption of methylene blue from aqueous solutions by synthetic montmorillonites of different compositions. Glass Physics and Chemistry, 42(2): 207-213. doi:10.1134/s1087659616020073.

Gong J-L, Zhang Y-L, Jiang Y, Zeng G-M, Cui Z-H, Liu K, . . Huan S-Y. (2015). Continuous adsorption of $\mathrm{Pb}(\mathrm{II})$ and methylene blue by engineered graphite oxide coated sand in fixed-bed column. Applied Surface Science, 330: 148-157. doi:10.1016/j.apsusc.2014.11.068.

Guo Y-P, Wang H-J, Guo Y-J, Guo L-H, Chu L-F, \& Guo C-X. (2011). Fabrication and characterization of hierarchical ZSM- 5 zeolites by using organosilanes as additives. Chemical Engineering Journal, 166(1): 391-400. doi:10.1016/j.cej.2010.10.057.

Han R, Zhang J, Han P, Wang Y, Zhao Z, \& Tang M. (2009). Study of equilibrium, kinetic and thermodynamic parameters about methylene blue adsorption onto natural zeolite. Chemical Engineering Journal, 145(3): 496-504. doi:10.1016/j.cej.2008.05.003.

He K, Chen G, Zeng G, Chen A, Huang Z, Shi J, ... Hu L. (2018). Enhanced removal performance for methylene blue by kaolin with graphene oxide modification. Journal of the Taiwan Institute of Chemical Engineers, 89: 77-85. doi:10.1016/j.jtice.2018.04.013.

Huang T, Yan M, He K, Huang Z, Zeng G, Chen A, ... Chen G. (2019). Efficient removal of methylene blue from aqueous solutions using magnetic graphene oxide modified zeolite. Journal of Colloid and Interface Science, 543: 43-51. doi:10.1016/j.jcis.2019.02.030.

Jawad A H, \& Abdulhameed A S. (2020). Mesoporous Iraqi red kaolin clay as an efficient adsorbent for methylene blue dye: Adsorption kinetic, isotherm and mechanism study. Surfaces and Interfaces, 18. doi:10.1016/j.surfin.2019.100422.

Jin J, Zhang X, Li Y, Li H, Wu W, Cui Y, ... Shi J. (2012). A Simple Route to Synthesize Mesoporous ZSM-5 Templated by Ammonium-Modified Chitosan. Chemistry - A European Journal, 18(51): 16549-16555. doi:10.1002/chem.201201614.

Jin X, Jiang M-q, Shan X-q, Pei Z-g, \& Chen Z. (2008). Adsorption of methylene blue and orange II onto unmodified and surfactant-modified zeolite. Journal of Colloid and Interface Science, 328(2): 243-247. doi:10.1016/j.jcis.2008.08.066.

Khodaie M, Ghasemi N, Moradi B, \& Rahimi M. (2013). Removal of Methylene Blue from Wastewater by Adsorption onto ZnCl2Activated Corn Husk Carbon Equilibrium Studies. Journal of Chemistry, 2013: 1-6. doi:10.1155/2013/383985.

Krishnamurthy M, Msm K, \& Kanakkampalayam Krishnan C. (2016). Hierarchically structured MFI zeolite monolith prepared using agricultural waste as solid template. Microporous and Mesoporous Materials, 221: 23-31. doi:10.1016/j.micromeso.2015.09.022.

Kumari S, Khan A A, Chowdhury A, Bhakta A K, Mekhalif Z, \& Hussain S. (2020). Efficient and highly selective adsorption of cationic dyes and removal of ciprofloxacin antibiotic by surface modified nickel sulfide nanomaterials: Kinetics, isotherm and adsorption mechanism. Colloids and Surfaces A: Physicochemical and Engineering Aspects, 586. doi:10.1016/j.colsurfa.2019.124264.

Ma Y, Hu J, Jia L, Li Z, Kan Q, \& Wu S. (2013). Synthesis, characterization and catalytic activity of a novel mesoporous ZSM-5 zeolite. Materials Research Bulletin, 48(5): 1881-1884. doi:10.1016/j.materresbull.2013.01.014.

Mall I D, Srivastava V C, \& Agarwal N K. (2006). Removal of Orange-G and Methyl Violet dyes by adsorption onto bagasse fly ash-kinetic study and equilibrium isotherm analyses. Dyes and Pigments, 69(3): 210-223. doi:10.1016/j.dyepig.2005.03.013. 
Miyah Y, Lahrichi A, Idrissi M, Khalil A, \& Zerrouq F. (2018). Adsorption of methylene blue dye from aqueous solutions onto walnut shells powder: Equilibrium and kinetic studies. Surfaces and Interfaces, 11: 74-81. doi:10.1016/j.surfin.2018.03.006.

Mouni L, Belkhiri L, Bollinger J-C, Bouzaza A, Assadi A, Tirri A, ... Remini H. (2018). Removal of Methylene Blue from aqueous solutions by adsorption on Kaolin: Kinetic and equilibrium studies. Applied Clay Science, 153: 38-45. doi:10.1016/j.clay.2017.11.034.

Narayanan S, Vijaya J J, Sivasanker S, Ragupathi C, Sankaranarayanan T M, \& Kennedy L J. (2016). Hierarchical ZSM-5 catalytic performance evaluated in the selective oxidation of styrene to benzaldehyde using TBHP. Journal of Porous Materials, 23(3): 741-752. doi:10.1007/s10934016-0129-8.

Narayanan S, Vijaya J J, Sivasanker S, Yang S, \& Kennedy L J. (2014). Hierarchical ZSM-5 catalyst synthesized by a Triton X-100 assisted hydrothermal method. Chinese Journal of Catalysis, 35(11): 1892-1899. doi:10.1016/s1872-2067(14)60177-7.

Nas M S, Calimli M H, Burhan H, Yılmaz M, Mustafov S D, \& Sen F. (2019). Synthesis, characterization, kinetics and adsorption properties of Pt-Co@GO nano-adsorbent for methylene blue removal in the aquatic mediums using ultrasonic process systems. Journal of Molecular Liquids, 296. doi:10.1016/j.molliq.2019.112100.

Naushad M, Alqadami A A, AlOthman Z A, Alsohaimi I H, Algamdi M S, \& Aldawsari A M. (2019). Adsorption kinetics, isotherm and reusability studies for the removal of cationic dye from aqueous medium using arginine modified activated carbon. Journal of Molecular Liquids, 293. doi:10.1016/j.molliq.2019.111442.

Noor P, Khanmohammadi M, Roozbehani B, Yaripour F, \& Bagheri Garmarudi A. (2018). Introduction of table sugar as a soft second template in ZSM- 5 nanocatalyst and its effect on product distribution and catalyst lifetime in methanol to gasoline conversion. Journal of Energy Chemistry, 27(2): 582-590. doi:10.1016/j.jechem.2017.10.031.

Pang X, Sellaoui L, Franco D, Netto M S, Georgin J, Luiz Dotto G, . . L Li Z. (2020). Preparation and characterization of a novel mountain soursop seeds powder adsorbent and its application for the removal of crystal violet and methylene blue from aqueous solutions. Chemical Engineering Journal, 391. doi:10.1016/j.cej.2019.123617.

Pomicpic J, Dancel G C, Cabalar P J, \& Madrid J. (2020). Methylene blue removal by poly(acrylic acid)grafted pineapple leaf fiber/polyester nonwoven fabric adsorbent and its comparison with removal by gamma or electron beam irradiation. Radiation Physics and Chemistry, 172. doi:10.1016/j.radphyschem.2020.108737.

Radoor S, Karayil J, Jayakumar A, Parameswaranpillai J, \& Siengchin S. (2021). An efficient removal of malachite green dye from aqueous environment using ZSM-5 zeolite/polyvinyl alcohol/carboxymethyl cellulose/sodium alginate bio composite. Journal of Polymers and the Environment. doi:10.1007/s10924-020-02024-y.

Radoor S, Karayil J, Parameswaranpillai J, \& Siengchin S. (2020a). Adsorption Study of Anionic Dye, Eriochrome Black T from Aqueous Medium Using Polyvinyl Alcohol/Starch/ZSM-5 Zeolite Membrane. Journal of Polymers and the Environment, 28(10): 2631-2643. doi:10.1007/s10924-020-01812-w.

Radoor S, Karayil J, Parameswaranpillai J, \& Siengchin S. (2020b). Removal of anionic dye Congo red from aqueous environment using polyvinyl alcohol/sodium alginate/ZSM-5 zeolite membrane. Scientific Reports, 10(1). doi:10.1038/s41598-020-72398-5.

Rida K, Bouraoui S, \& Hadnine S. (2013). Adsorption of methylene blue from aqueous solution by kaolin and zeolite. Applied Clay Science, 83-84: 99-105. doi:10.1016/j.clay.2013.08.015.

Sabarish R, Jasila K, Aswathy J, Jyotishkumar P, \& Suchart S. (2020). Fabrication of PVA/agar/modified ZSM-5 zeolite membrane for removal of anionic dye from aqueous solution. International Journal of Environmental Science and Technology. doi:10.1007/s13762-020-02998-1. 
Sabarish R, \& Unnikrishnan G. (2017). Synthesis, characterization and catalytic activity of hierarchical ZSM-5 templated by carboxymethyl cellulose. Powder Technology, 320: 412-419. doi:10.1016/j.powtec.2017.07.041.

Sabarish R, \& Unnikrishnan G. (2018a). Novel biopolymer templated hierarchical silicalite-1 as an adsorbent for the removal of rhodamine B. Journal of Molecular Liquids, 272: 919-929. doi:10.1016/j.molliq.2018.10.093.

Sabarish R, \& Unnikrishnan G. (2018b). Polyvinyl alcohol/carboxymethyl cellulose/ZSM-5 zeolite biocomposite membranes for dye adsorption applications. Carbohydrate Polymers, 199: 129-140. doi:10.1016/j.carbpol.2018.06.123.

Sabarish R, \& Unnikrishnan G. (2018c). PVA/PDADMAC/ZSM-5 zeolite hybrid matrix membranes for dye adsorption: Fabrication, characterization, adsorption, kinetics and antimicrobial properties. Journal of Environmental Chemical Engineering, 6(4): 3860-3873. doi:10.1016/j.jece.2018.05.026.

Sabarish R, \& Unnikrishnan G. (2019). Synthesis, characterization and evaluations of micro/mesoporous ZSM-5 zeolite using starch as bio template. SN Applied Sciences, 1(9). doi:10.1007/s42452-019-1036-9.

Sabarish R, \& Unnikrishnan G. (2020). A novel anionic surfactant as template for the development of hierarchical ZSM-5 zeolite and its catalytic performance. Journal of Porous Materials, 27(3): 691-700. doi:10.1007/s10934-019-00852-5.

Sari Z G L V, Younesi H, \& Kazemian H. (2014). Synthesis of nanosized ZSM-5 zeolite using extracted silica from rice husk without adding any alumina source. Applied Nanoscience, 5(6): 737-745. doi:10.1007/s13204-014-0370-x.

Sartape A S, Mandhare A M, Jadhav V V, Raut P D, Anuse M A, \& Kolekar S S. (2017). Removal of malachite green dye from aqueous solution with adsorption technique using Limonia acidissima (wood apple) shell as low cost adsorbent. Arabian Journal of Chemistry, 10: S3229-S3238. doi:10.1016/j.arabjc.2013.12.019.

Sharifpour E, Khafri H Z, Ghaedi M, Asfaram A, \& Jannesar R. (2018). Isotherms and kinetic study of ultrasound-assisted adsorption of malachite green and $\mathrm{Pb} 2+$ ions from aqueous samples by copper sulfide nanorods loaded on activated carbon: Experimental design optimization. Ultrasonics Sonochemistry, 40: 373-382. doi:10.1016/j.ultsonch.2017.07.030.

Sharma P, Kaur R, Baskar C, \& Chung W-J. (2010). Removal of methylene blue from aqueous waste using rice husk and rice husk ash. Desalination, 259(1-3): 249-257. doi:10.1016/j.desal.2010.03.044.

Shittu I, Achazhiyath Edathil A, Alsaeedi A, Al-Asheh S, Polychronopoulou K, \& Banat F. (2019). Development of novel surfactant functionalized porous graphitic carbon as an efficient adsorbent for the removal of methylene blue dye from aqueous solutions. Journal of Water Process Engineering, 28: 69-81. doi:10.1016/j.jwpe.2019.01.001.

Shooto N D, Thabede P M, Bhila B, Moloto H, \& Naidoo E B. (2020). Lead ions and methylene blue dye removal from aqueous solution by mucuna beans (velvet beans) adsorbents. Journal of Environmental Chemical Engineering, 8(2). doi:10.1016/j.jece.2019.103557.

Sizmur T, Fresno T, Akgül G, Frost H, \& Moreno-Jiménez E. (2017). Biochar modification to enhance sorption of inorganics from water. Bioresource Technology, 246: 34-47. doi:10.1016/j.biortech.2017.07.082.

Soliman N k, Moustafa A F, Aboud A A, \& Halim K S A. (2019). Effective utilization of Moringa seeds waste as a new green environmental adsorbent for removal of industrial toxic dyes. Journal of Materials Research and Technology, 8(2): 1798-1808. doi:10.1016/j.jmrt.2018.12.010.

Stavrinou A, Aggelopoulos C A, \& Tsakiroglou C D. (2018). Exploring the adsorption mechanisms of cationic and anionic dyes onto agricultural waste peels of banana, cucumber and potato: Adsorption kinetics and equilibrium isotherms as a tool. Journal of Environmental Chemical Engineering, 6(6): 6958-6970. doi:10.1016/j.jece.2018.10.063. 
Sun H, Cao L, \& Lu L. (2011). Magnetite/reduced graphene oxide nanocomposites: One step solvothermal synthesis and use as a novel platform for removal of dye pollutants. Nano Research, 4(6): 550-562. doi:10.1007/s12274-011-0111-3.

Talaiekhozani A, Reza Mosayebi M, Fulazzaky M A, Eskandari Z, \& Sanayee R. (2020). Combination of $\mathrm{TiO} 2$ microreactor and electroflotation for organic pollutant removal from textile dyeing industry wastewater. Alexandria Engineering Journal, 59(2): 549-563. doi:10.1016/j.aej.2020.01.052.

Tao H, Li C, Ren J, Wang Y, \& Lu G. (2011). Synthesis of mesoporous zeolite single crystals with cheap porogens. Journal of Solid State Chemistry, 184(7): 1820-1827. doi:10.1016/j.jssc.2011.05.023.

Tkaczyk A, Mitrowska K, \& Posyniak A. (2020). Synthetic organic dyes as contaminants of the aquatic environment and their implications for ecosystems: A review. Science of The Total Environment, 717. doi:10.1016/j.scitotenv.2020.137222.

Ullah R, Sun J, Gul A, \& Bai S. (2020). One-step hydrothermal synthesis of TiO2-supported clinoptilolite: An integrated photocatalytic adsorbent for removal of crystal violet dye from aqueous media. Journal of Environmental Chemical Engineering, 8(4). doi:10.1016/j.jece.2020.103852.

Vadivelan V, \& Kumar K V. (2005). Equilibrium, kinetics, mechanism, and process design for the sorption of methylene blue onto rice husk. Journal of Colloid and Interface Science, 286(1): 90-100. doi:10.1016/j.jcis.2005.01.007.

Vakili M, Deng S, Cagnetta G, Wang W, Meng P, Liu D, \& Yu G. (2019). Regeneration of chitosanbased adsorbents used in heavy metal adsorption: A review. Separation and Purification Technology, 224: 373-387. doi:10.1016/j.seppur.2019.05.040.

Wang S, \& Zhu Z. (2006). Characterisation and environmental application of an Australian natural zeolite for basic dye removal from aqueous solution. Journal of Hazardous Materials, 136(3): 946-952. doi:10.1016/j.jhazmat.2006.01.038.

Wang X S, Zhou Y, Jiang Y, \& Sun C. (2008). The removal of basic dyes from aqueous solutions using agricultural by-products. Journal of Hazardous Materials, 157(2-3): 374-385. doi:10.1016/j.jhazmat.2008.01.004.

Yin C, Feng L, Ni R, Hu L, Zhao X, \& Tian D. (2014). One-pot synthesis of hierarchically nanoporous ZSM-5 for catalytic cracking. Powder Technology, 253: 10-13. doi:10.1016/j.powtec.2013.10.027.

Zhao B, O'Connor D, Zhang J, Peng T, Shen Z, Tsang D C W, \& Hou D. (2018). Effect of pyrolysis temperature, heating rate, and residence time on rapeseed stem derived biochar. Journal of Cleaner Production, 174: 977-987. doi:10.1016/j.jclepro.2017.11.013. 
Figures

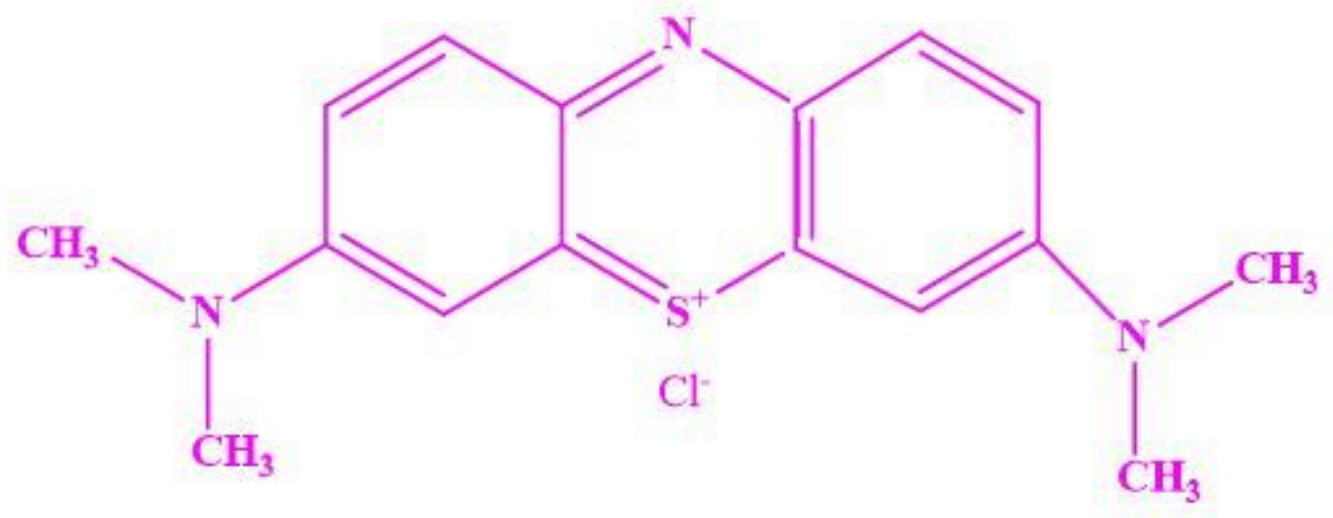

Figure 1

Structural formula of methylene blue dye.
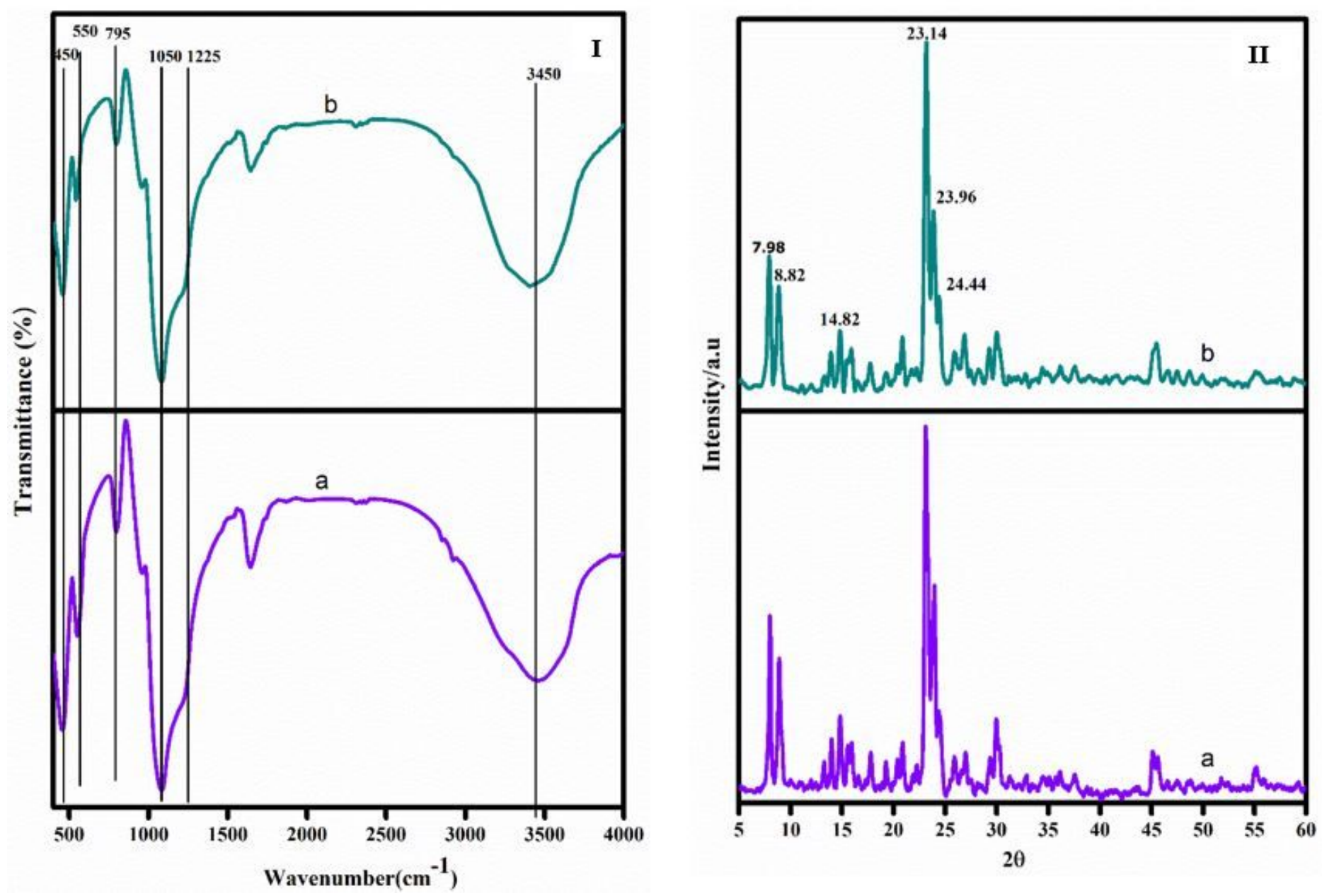

Figure 2 
I) FTIR spectra and II) XRD pattern of a) CZSM-5 b) PZSM-5

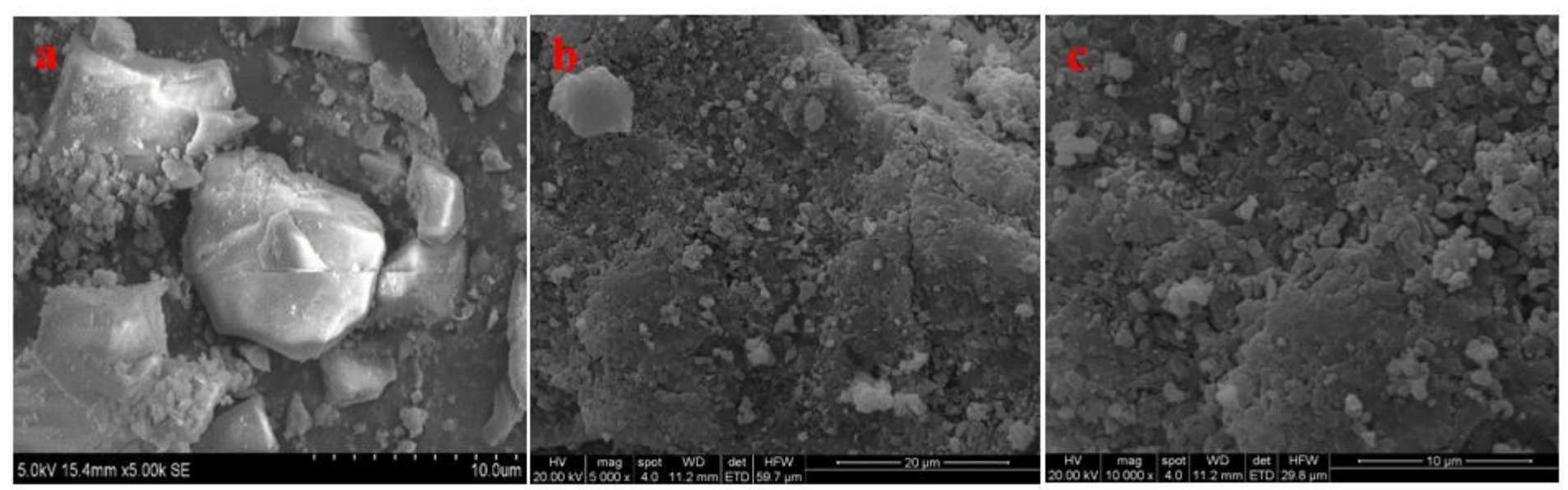

Figure 3

SEM images of a) CZSM-5 (b \& c) PZSM-5
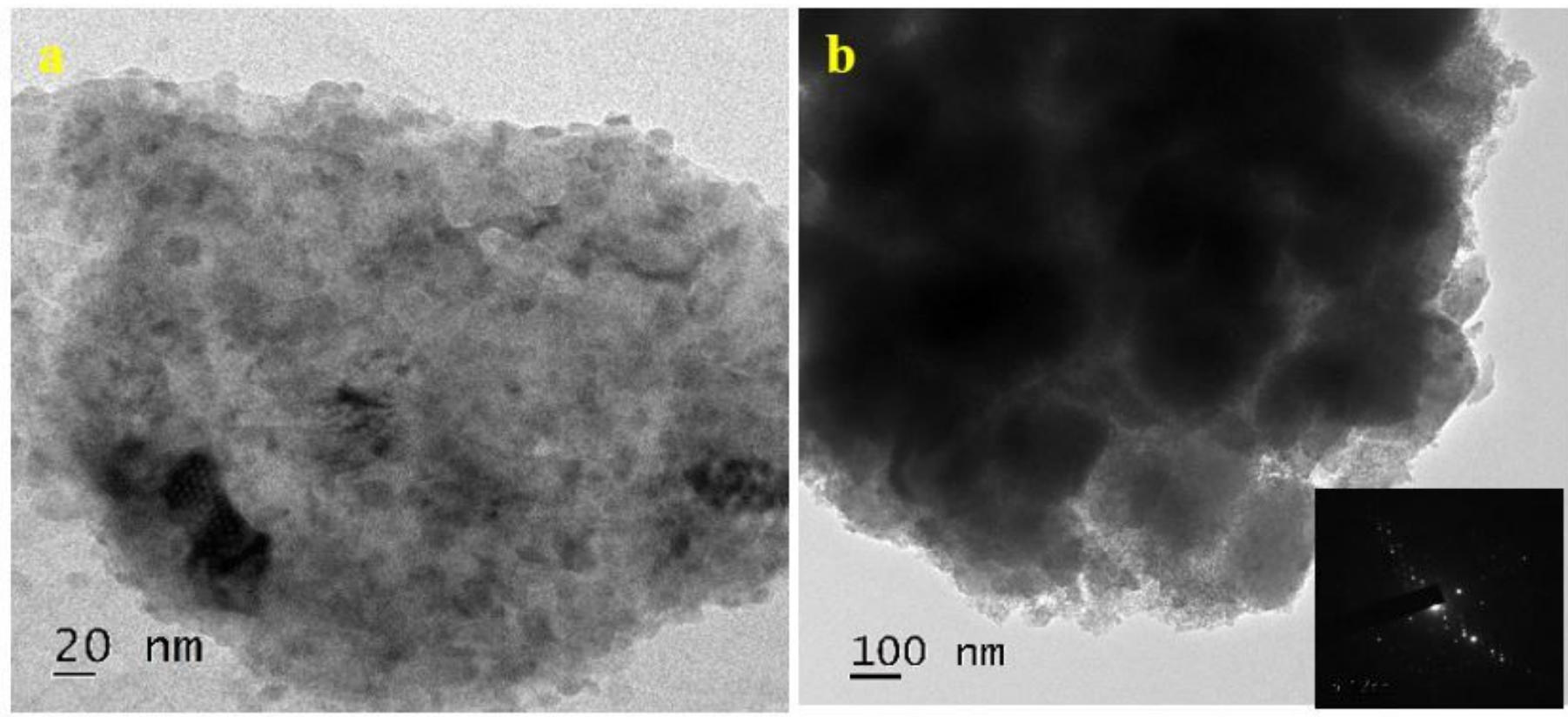

Figure 4

TEM images of PZSM-5 

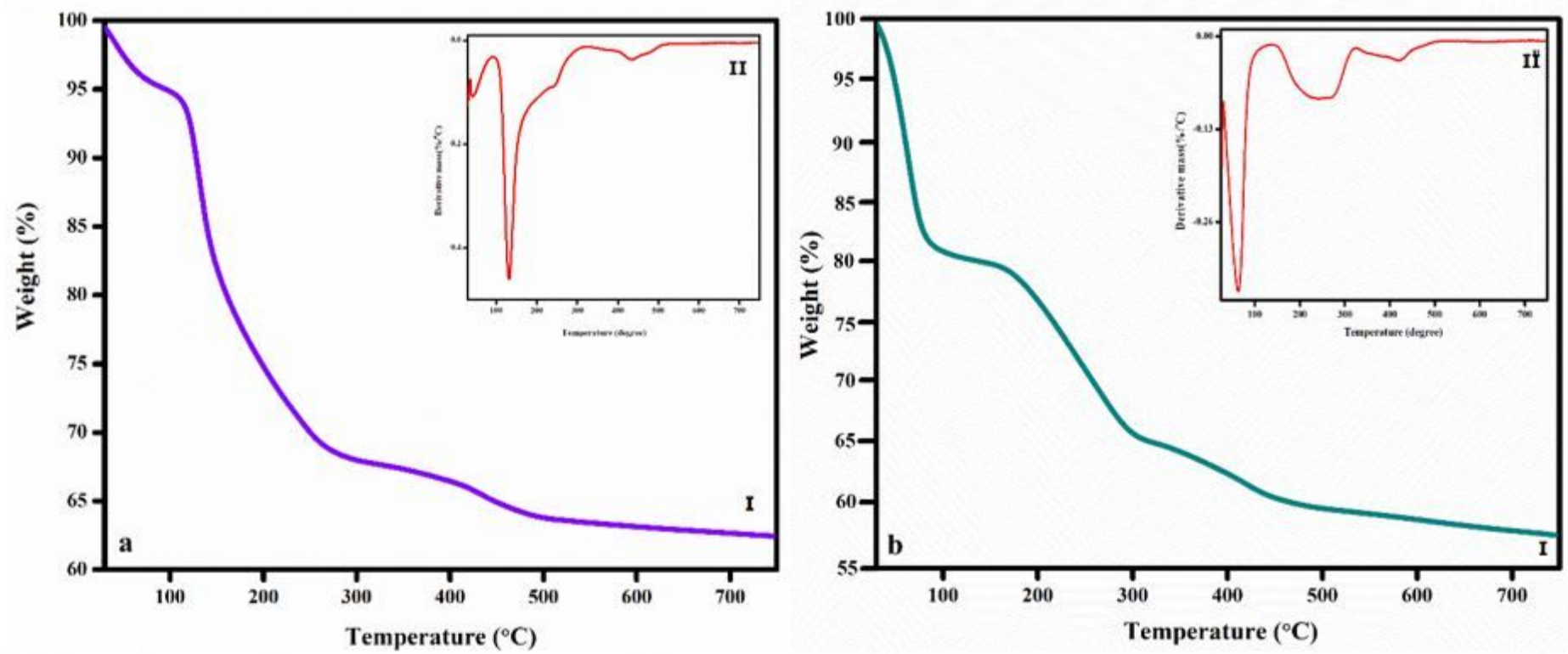

Figure 5

Thermogravimetric curve of: a) CZSM-5 b) PZSM-5 (DTG curves are given at the inset)
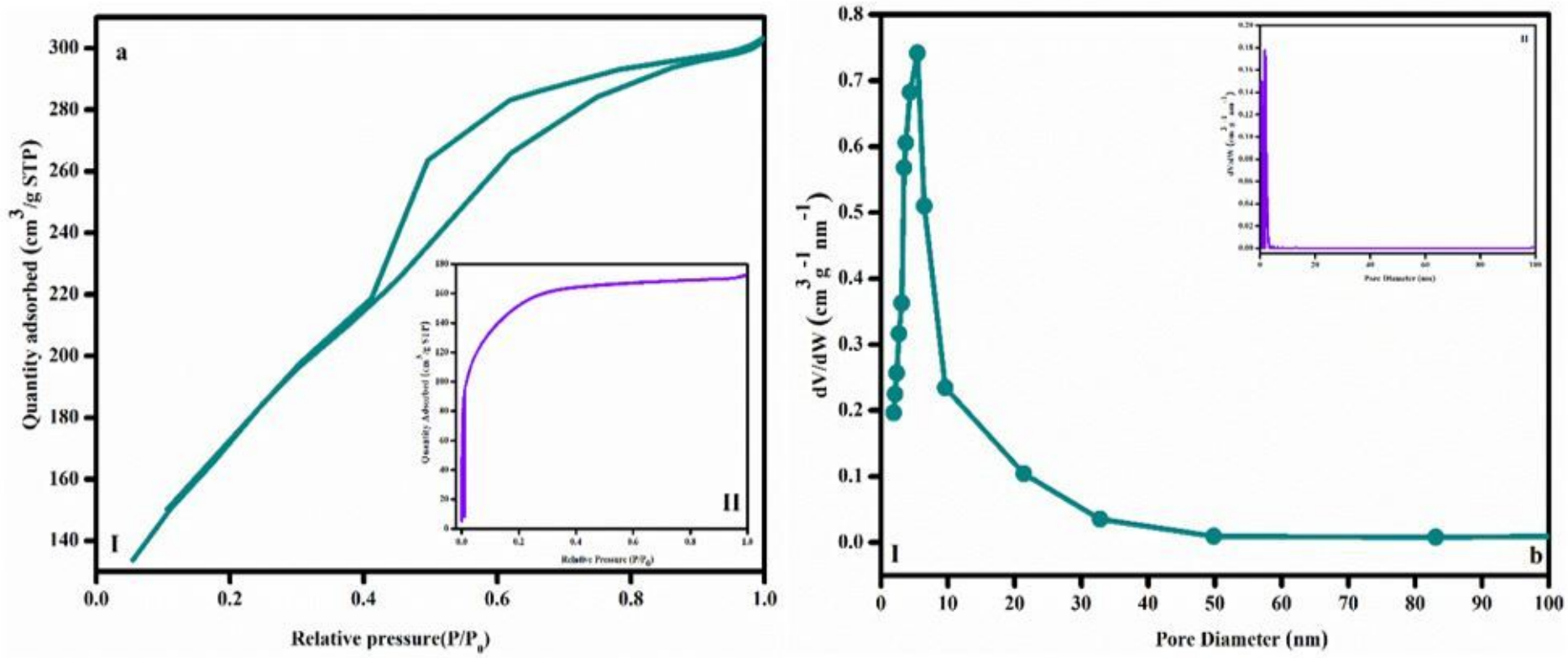

Figure 6

(a) Nitrogen adsorption-desorption isotherms of (i) PZSM-5 (ii) (inset) CZSM-5; (b) Pore size distribution curve of: (i) PZSM-5 (ii) (inset) CZSM-5 


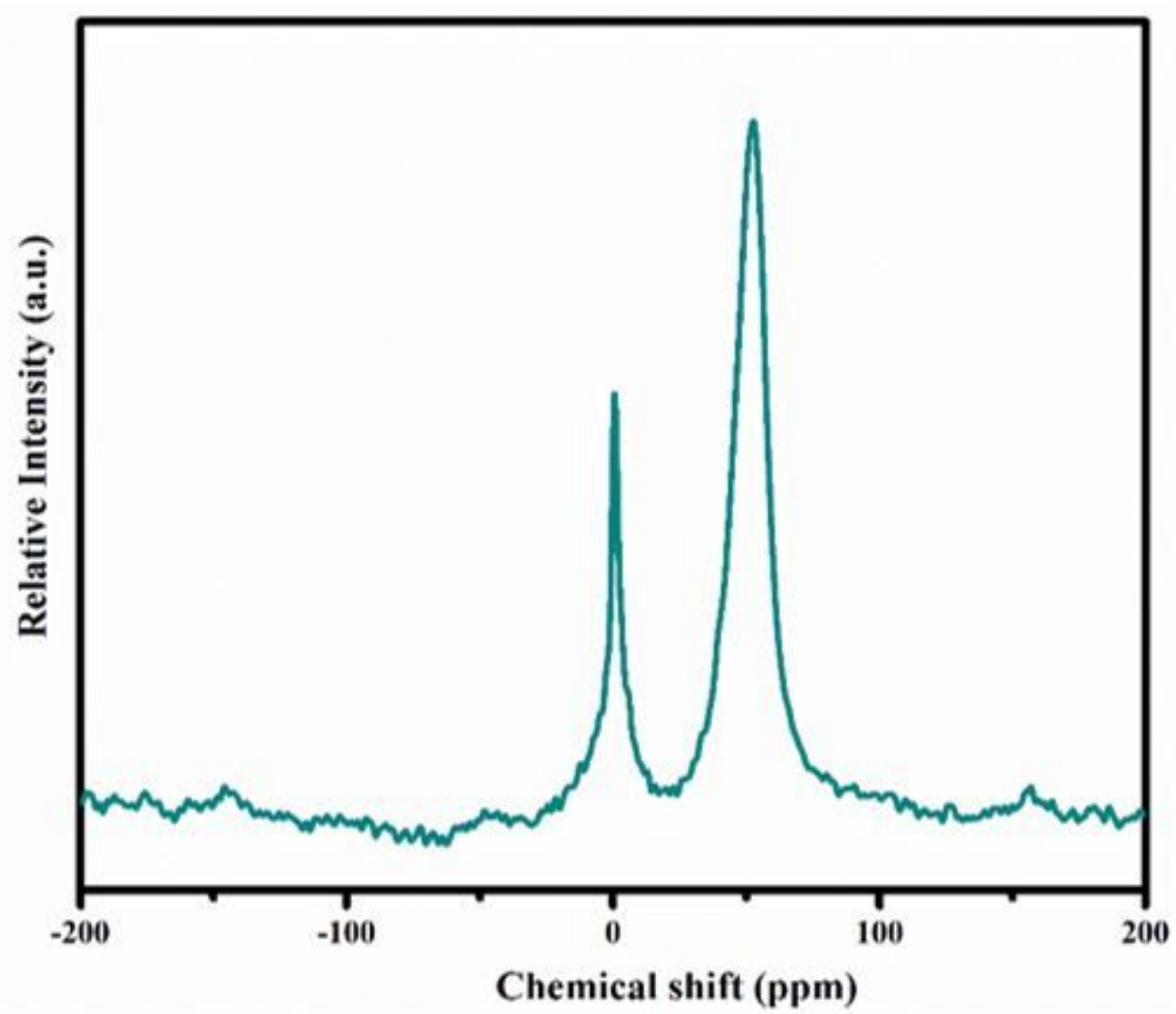

Figure 7

Solid state 27AINMR spectra of PZSM-5 

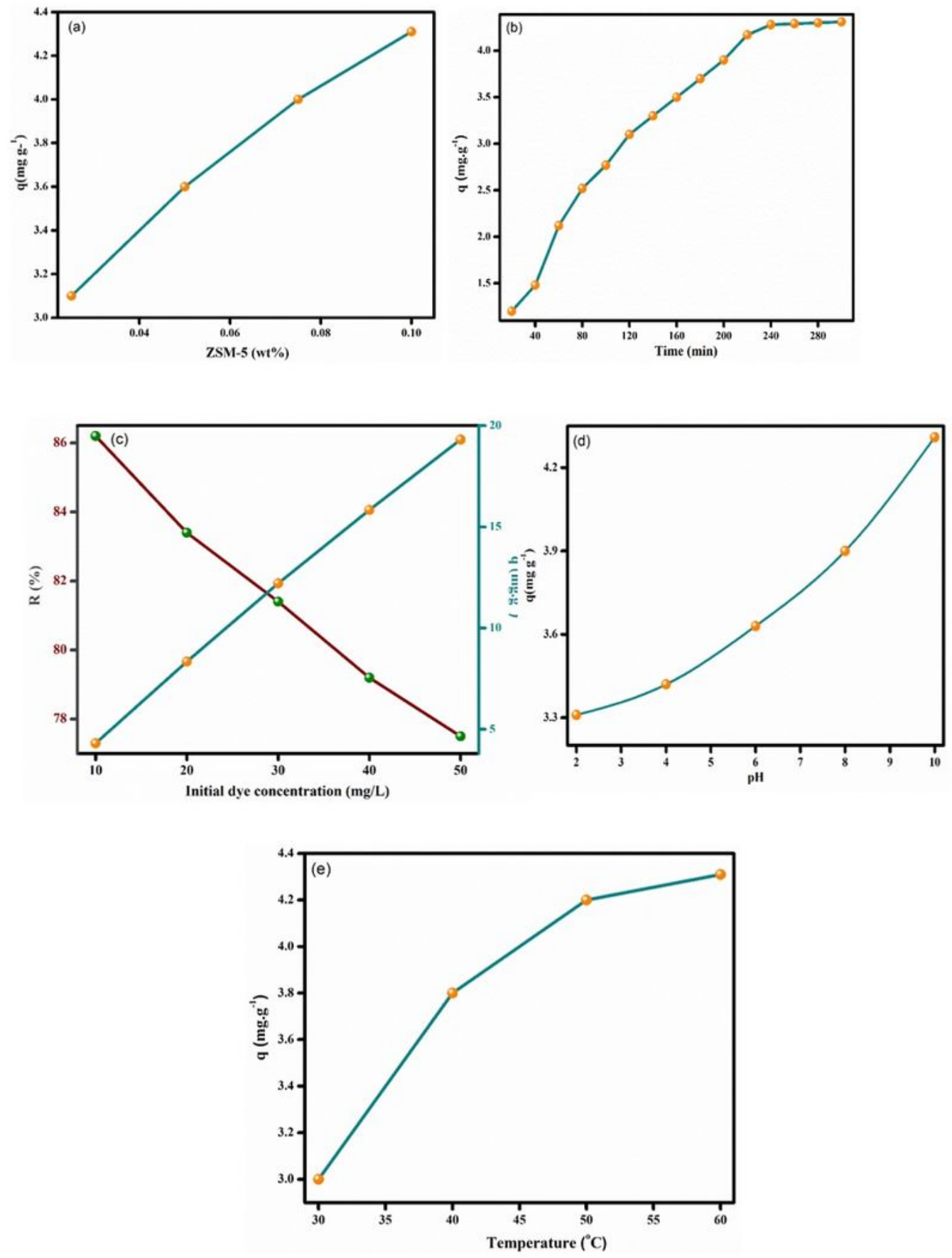

Figure 8

Effect of different parameters a) zeolite dosage; b) contact time; c) initial dye concentration; d) $\mathrm{pH}$; e) temperature on adsorption of MB on PDADMAC modified ZSM-5 

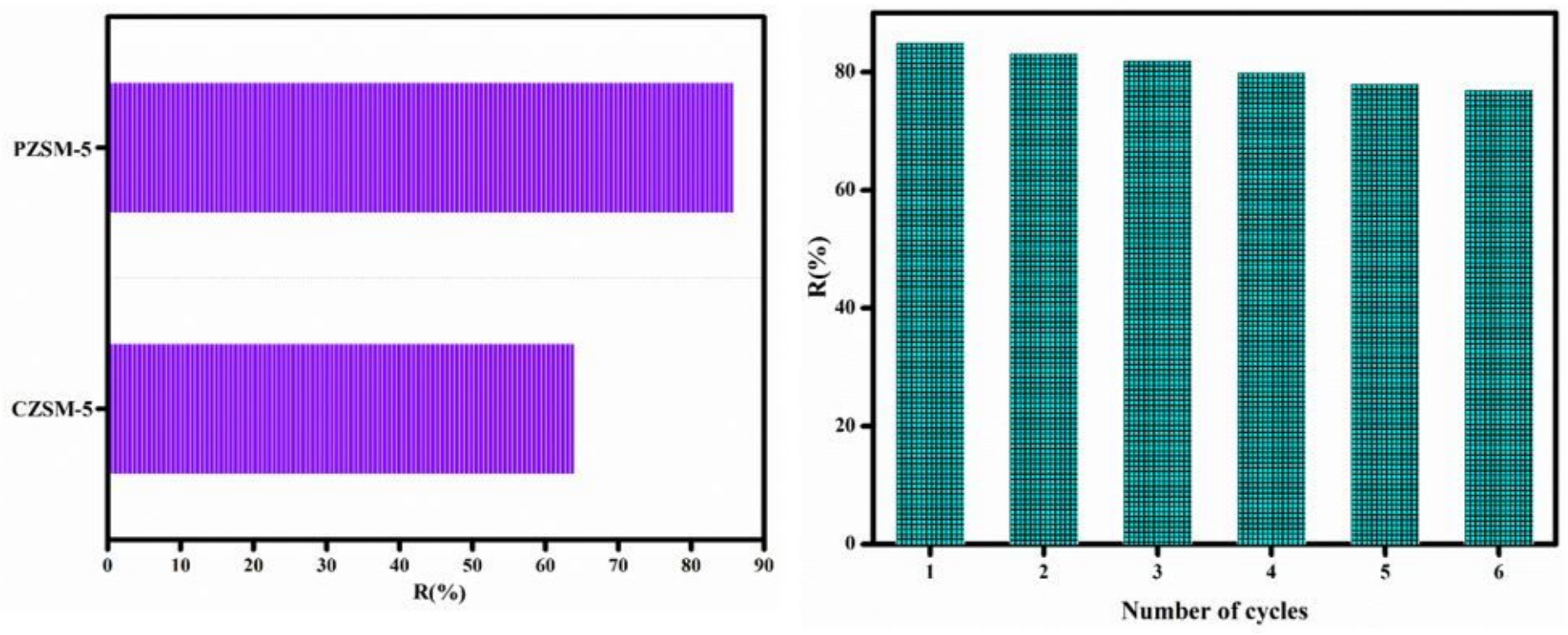

Figure 9

Effect of different type of zeolite and reusability of MB dye on PDADMAC modified ZSM-5
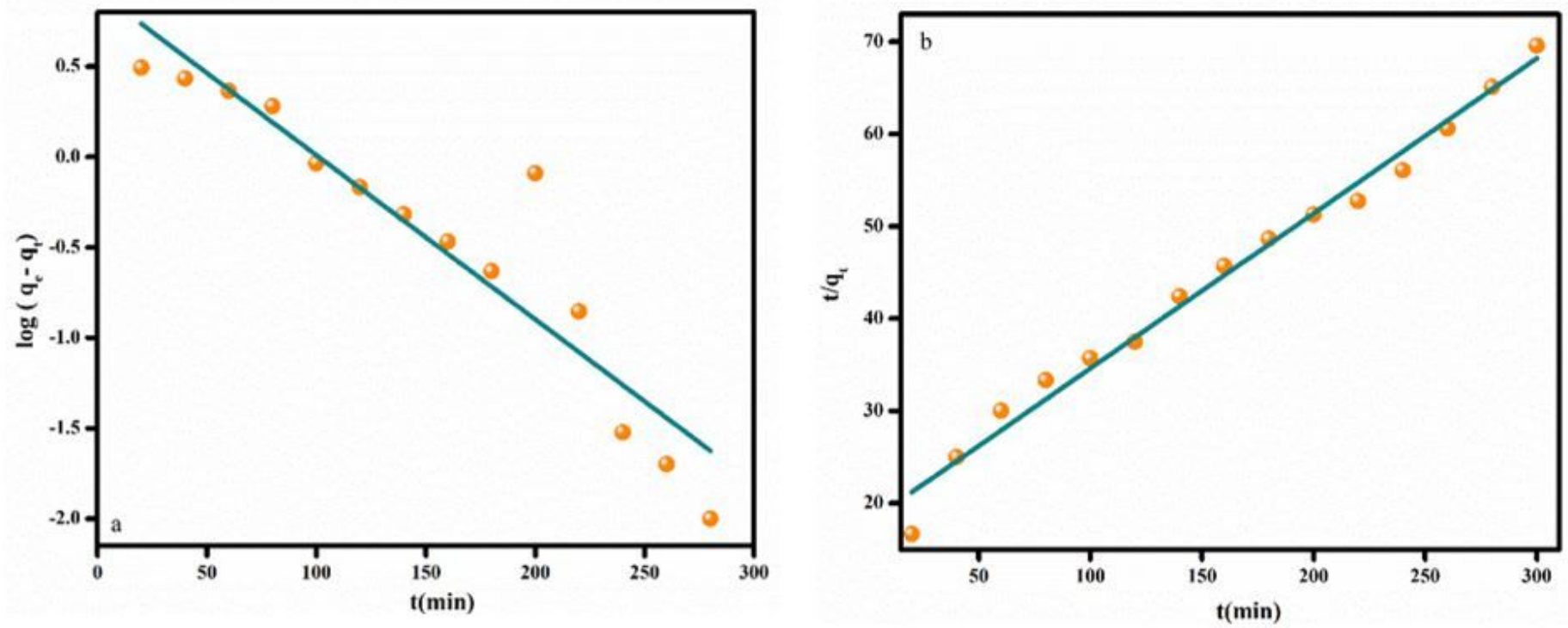

Figure 10

Linear kinetic plots of a) pseudo-first-order b) pseudo-second-order models for the adsorption of MB dye for the PDADMAC modified ZSM-5 zeolite 

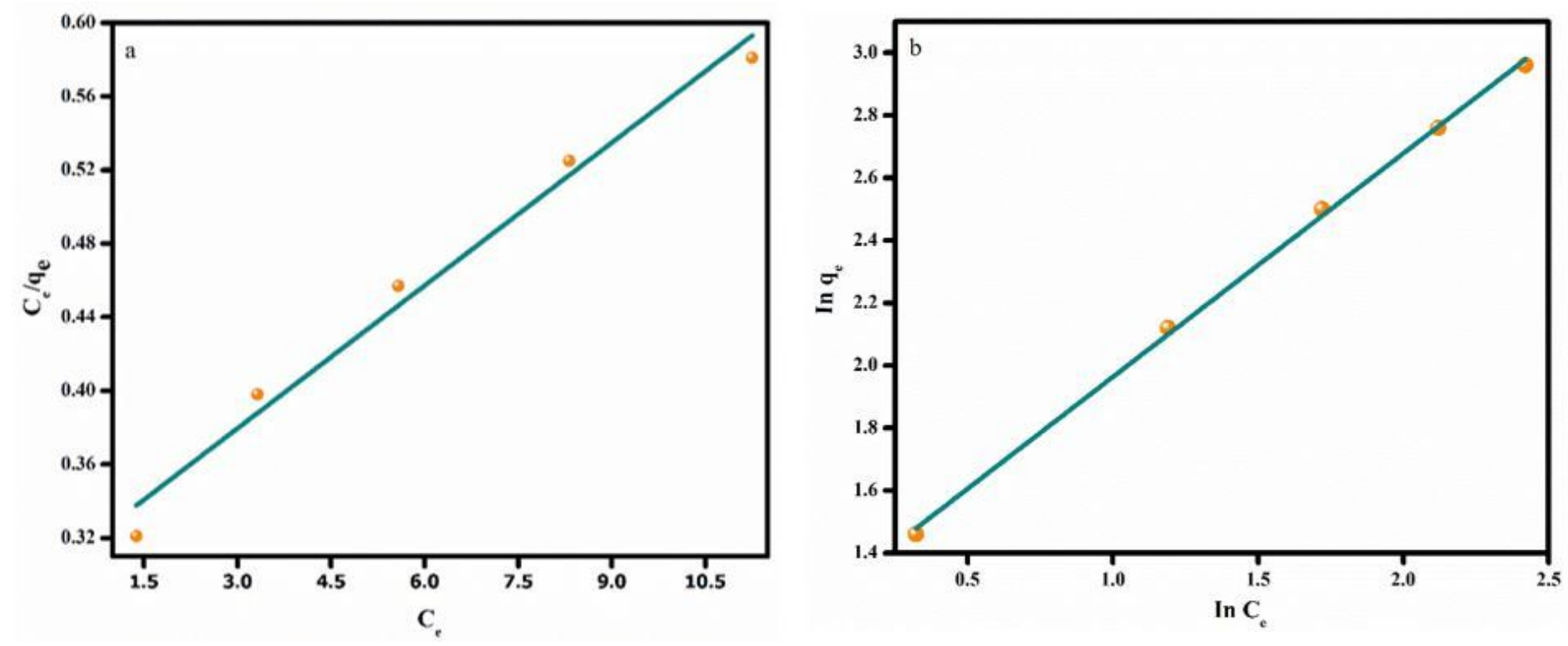

Figure 11

Linear isotherm plots of a) Langmuir b) Freundlich model for the adsorption of MB dye for the PDADMAC modified ZSM-5 zeolite

\section{Supplementary Files}

This is a list of supplementary files associated with this preprint. Click to download.

- Scheme1.jpg

- Scheme2.jpg 